\title{
Global Energy and Water Budgets in MERRA
}

Michael G. Bosilovich ${ }^{*}$ NASA/GSFC/GMAO

Franklin R. Robertson NASA/MSFC

Junye Chen U. Maryland/ESSIC and GMAO

NASA/Global Modeling and Assimilation Office

Code 610.1 Goddard Space Flight Center

Greenbelt MD

Submitted to MERRA Special Issue of Journal of Climate

* Corresponding address: Global Modeling and Assimilation Office, Code 610.1 NASA Goddard Space Flight Center, Greenbelt, MD 20771, Michael.Bosilovich@nasa.gov 


\section{ABSTRACT}

2 Reanalyses, retrospectively analyzing observations over climatological time scales, 3 represent a merger between satellite observations and models to provide globally continuous data

4 and have improved over several generations. Balancing the Earth's global water and energy

5 budgets has been a focus of research for more than two decades. Models tend to their own

6 climate while remotely sensed observations have had varying degrees of uncertainty. This study

7 evaluates the latest NASA reanalysis, called the Modern Era Retrospective-analysis for Research

8 and Applications (MERRA), from a global water and energy cycles perspective.

MERRA was configured to provide complete budgets in its output diagnostics, including

10 the Incremental Analysis Update (IAU), the term that represents the observations influence on

11 the analyzed states, alongside the physical flux terms. Precipitation in reanalyses is typically

12 sensitive to the observational analysis. For MERRA, the global mean precipitation bias and

13 spatial variability are more comparable to merged satellite observations (GPCP and CMAP) than

14 previous generations of reanalyses. Ocean evaporation also has a much lower value which is

15 comparable to observed data sets. The global energy budget shows that MERRA cloud effects

16 may be generally weak, leading to excess shortwave radiation reaching the ocean surface.

17 Evaluating the MERRA time series of budget terms, a significant change occurs, which

18 does not appear to be represented in observations. In 1999, the global analysis increments of

19 water vapor changes sign from negative to positive, and primarily lead to more oceanic

20 precipitation. This change is coincident with the beginning of AMSU radiance assimilation.

21 Previous and current reanalyses all exhibit some sensitivity to perturbations in the observation

22 record, and this remains a significant research topic for reanalysis development. The effect of the

23 changing observing system is evaluated for MERRA water and energy budget terms. 


\section{Introduction}

In the study of the Earth's climate, quantifying global water and energy cycling rates and

3 the associated physical processes more accurately is critical to understanding the climate and its

4 mechanisms of variability and change from global to local scales. The sun heats the atmosphere

5 and the surface, thus driving many processes including the transfer of energy and water and

6 ultimately dynamical transports of these quantities. Trenberth et al. (2009; henceforth TFK09)

7 provide discussion on the primary water and energy transfer processes, as well as recent

8 quantitative assessments of various observational data and uncertainties. Even though the TOA

9 radiative fluxes (please see the appendix for a list of all acronyms) likely have the smallest

10 uncertainties (order $5 \mathrm{Wm}^{-2}$ bias and perhaps an order of magnitude less in precision) refining

11 this observational record is still an active area of research (Loeb et al. 2009). Validating the

12 observed water cycle observations through global balance shows that the uncertainties are a

13 fundamental issue (Schlosser and Houser, 2007). While some observational uncertainty is

14 steadily narrowing, few of the processes have adequate observational representation. In this case,

15 modeled estimates of the energetics derived from retrospective-analyses (or reanalyses) have

16 been used to fill gaps in the data. But of course, models themselves, which represent our

17 understanding of the Earth's processes, are limited by computational resources and simplifying

18 assumptions. Models have their own uncertainty and can evolve their own climate, leading to

19 distinct bias when compared with available observations. Data assimilation can produce analyses

20 of the observed state that constrains the model's physical results. Retrospective-analyses (or

21 reanalyses) apply data assimilation across climate time scales in an effort to provide globally

22 continuous and consistent climate data that exploit both observations and models. However,

23 individual reanalyses still must contend with uncertainty, where for example, different reanalyses 
1 respond to global forcing with different circulation perturbations (Chen et al. 2008a). With

2 several generations of reanalyses to consider, the various data sets generated from these efforts

3 show large variance in the processes of the global water and energy budgets (Chen et al. 2008 a

4 and b, TFK09, Bosilovich et al., 2008 and 2009).

5 Kalnay et al. (1996), Uppala et al. (2005) and Onogi et al. (2007) provide some of the

6 most important overviews of existing long global reanalyses. In this study, we evaluate the

7 global energy and water cycles of a new reanalysis, NASA's Modern Era Retrospective-analysis

8 for Research and Applications (MERRA, Rienecker et al. 2010). MERRA data are derived from

9 the Goddard Earth Observing System (GEOS) version 5 data assimilation system, which is a

10 combination of a NASA general circulation model (Rienecker et al. 2007) and the Gridpoint

11 Statistical Interpolation (GSI) analysis developed in collaboration with the National Centers for

12 Environmental Prediction (NCEP). During the validation of GEOS-5 and preparations for

13 MERRA, special attention was given to the water and energy cycles; however, the validation

14 experiments themselves were limited in time (e.g. Bosilovich et al. 2008). Given the established

15 biases in space and time of the water and energy cycles in existing reanalyses, MERRA water

16 and energy cycles need to be diagnostically characterized in comparison with the available

17 observations and reanalyses.

19 2. Data

20 a. Reanalyses

21 There exist several atmospheric reanalyses for the period of 1979 through 2005. The

22 Japanese 25 year Reanalysis (JRA-25) is quite recent, released for use in March 2006 (Onogi et

23 al., 2005, 2007), the 45 year ECMWF reanalysis (ERA-40, Uppala et al. 2005), which stops in 
1 August 2002 and the National Centers for Environmental Prediction (NCEP) second reanalysis

2 (NCEP-DOE, Kanamitsu et al. 2002) represent the second generation of reanalyses. More

3 recently, ECMWF has also released a short period (1989-present) Interim reanalysis with their

4 latest data assimilation system (Simmons et al., 2007; Uppala et al., 2008). The NCEP CFSR

5 (Saha et al. 2010) became available in early 2010. While all these reanalyses assimilate

6 observations over the recent climate record, new reanalyses will continue to be produced because

7 of updated model physical processes, enhanced data assimilation methods, increased availability

8 of computing resource, growing types of observations available for assimilation and improved 9 observational quality control.

While the data assimilation and numerical model components of the reanalysis system are

11 fixed for the processing of the climate period (as proposed by Bengtsson and Shukla, 1988;

12 Trenberth and Olson, 1988), the observing system changes greatly in time. A major change to the

13 observational record concerns the onset of routine operational remote sensing soundings, starting

14 with TIROS-N followed by NOAA-6 in 1979, where primarily conventional (e.g. radiosonde and

15 surface stations) were previously available. Bengtsson et al. (2004) studied the full 40 year time

16 series of ERA-40 and found that unrealistic trends occurred related to increased satellite

17 observations in 1979. However, even during the modern satellite observing period, new satellites

18 and measurements start and end at irregular intervals, and ultimately, any given satellite has an

19 expected lifetime on the order of 10 years, much shorter than what is needed for climate studies.

20 So, there are numerous changes to the remotely sensed data record (Rienecker et al. 2010) that

21 involve not only calibration (bias) but also measurement sensitivity and sampling density. These

22 variations during the satellite era can lead to systematic changes in the reanalysis time series. For

23 example, the JRA-25 precipitation record is sensitive to the availability of microwave total 
1 column water retrievals (Onogi et al. 2005; Bosilovich et al. 2008) beginning in 1987 with the

$2 \mathrm{SSM} / \mathrm{I}$ operational satellites.

While analysis state variables are most closely related to observations, the variability of

4 the physical processes and fluxes among reanalyses can be substantial (Bosilovich et al 2009).

5 Much of the reanalysis data that provide information about the Earth's water and energy budgets

6 come from the model physics, which has been categorized as being closely related to the

7 numerical model as opposed to the analyzed state fields (Kalnay et al. 1996). Despite the

8 shortcomings, a particular advantage of reanalyses in climate studies is the availability of all or

9 many of the Earth's energy and water budget component fluxes. For example, NCEP reanalyses

10 have played a significant role in the development of global merged observational precipitation

11 (CMAP, Xie and Arkin, 1996) and ocean evaporation (Yu and Weller, 2007). Ultimately,

12 activities such as hydrologic applications would like to make use of reanalyses, but the accuracy

13 of model physics that control the fluxes requires further development (e.g. Maurer et al. 2001).

14 The physical terms of the reanalysis budgets generally do not balance even over long periods,

15 because the atmospheric data assimilation provides additional constraint (or forcing) in the

16 balance of the output data. This is ultimately presented as a residual term in many studies (Roads

17 and Betts, 2000; Roads et al. 2002). This term, referred to here as the analysis increment, reflects

18 the observations affect on the analysis, and so, as the observations change so do the forcing and

19 the physical response of the model to the forcing. With this term quantified, the budgets can be

20 studied closely, and some work has used the information to apply corrections to the physical

21 terms (Schubert and Chang, 1996; Bosilovich and Schubert, 2001; Robertson et al. 2010).

In reviewing the observed global energy budget, TFK09 also compared the reanalysis

23 energy budgets (specifically, ERA-40 NCEP-DoE R2 and JRA-25), and some similar biases are 
1 evident. Firstly, the net TOA energy did not balance well, with too much upward flux. However,

2 JRA-25 bias is related to too much OLR, while NCEP-DoE R2 is due to too much reflected

3 shortwave radiation, but both imbalances were on the order of $10 \mathrm{~W} / \mathrm{m}^{-2}$. Also, all reanalyses had

4 excessive evaporation and precipitation leading to stronger global hydrologic cycling. One aspect

5 of the reanalyses budgets not addressed by TFK09 is the atmospheric imbalance related to the

6 analysis increment. The observations can act as a source or sink of water and energy, and in their

7 study, the assimilated observational analysis generally add energy to the system though it is

8 dissipated in different ways.

9 b. MERRA

MERRA is a reanalysis of the satellite era (1979-present) using the GEOS-5 data

11 assimilation system. Rienecker et al. (2007) thoroughly describe the MERRA/GEOS-5 numerical

12 model and data assimilation system, while Rienecker et al (2010) describe the MERRA project.

13 In addition to the conventional observations (radiosonde, station, aircraft, ship), SSM/I radiances

14 and various sensor's retrieved winds, TIROS Operational Vertical Sounder (TOVS) radiances,

15 Atmospheric Infrared Sounder (AIRS) radiances, and scatterometer wind retrievals (to name a

16 few) are also assimilated. The experiments were initialized with spun up states from a long

17 climate model simulation, then 2 years of coarse real data assimilation followed by at least 4

18 years of real data assimilation (i.e. using the actual observations at the native horizontal

19 resolution, not spinning the same year over again) at the MERRA native grid (Rienecker et al.

202010 describes the spin up experiments). The native MERRA grid has a spatial resolution of $1 \frac{1}{2}{ }^{\circ}$

21 latitude by $2 / 3^{\circ}$ longitude with 72 hybrid model levels in the vertical (Suarez et al. 2010). The

22 analysis is performed by the NCEP Gridpoint Statistical Interpolation (GSI; Wu et al 2002). The

23 model is then updated with an additional model segment that includes an Incremental Analysis 
1 Update, IAU, in the budget equations (Bloom et al. 1996). The shock of the analysis at the

2 forecast initialization is greatly reduced, so that the spin down of physical fields (e.g.

3 precipitation) is a small factor in this system. This is also where observations affect the model's

4 governing equations (discussed in the next section). Bosilovich et al. (2008) evaluate

5 precipitation from the GEOS-5 data assimilation validation experiments for the months of

6 January and July 2004 and compare with the existing reanalyses and merged satellite

7 observations of precipitation GPCP and CMAP to assess the character of the monthly

8 precipitation prior to the production of MERRA. The results were promising but limited due to

9 the short period of the validation experiments, and will be briefly revisited later in this study.

$10 \quad$ c. Budget Equations

11 MERRA output diagnostics encompass all the variables required to balance energy and

12 mass budgets for the atmosphere and land. The MERRA enthalpy budget is produced, where

$13 H=\overline{c_{p} T_{v}}\left(c_{p}\right.$ is the heat capacity of dry air at constant pressure and $T_{v}$ is the virtual temperature).

14 The enthalpy tendency terms are:

$15 \frac{\partial H}{\partial t}=-\nabla \cdot \overline{\left(\vec{V} c_{p} T_{v}\right)}+\overline{\omega \alpha}+\left[\frac{\partial H}{\partial t}\right]_{R A D}+\left[\frac{\partial H}{\partial t}\right]_{M S T}+\left[\frac{\partial H}{\partial t}\right]_{A N A}+\left[\frac{\partial H}{\partial t}\right]_{T R B}+\mathcal{R}$

16 Overbars denote a vertical integration over the mass of the atmosphere. The first two terms on

17 the right hand side of the equation represent the convergence and release of potential energy. The

18 other tendencies represent radiation (RAD), moist processes (MST), turbulent diffusion (TRB, in

19 this example, the sensible heat flux). The analysis increment (ANA) is the tendency that is added

20 to the prognostic budgets due to the observational analysis. $\mathcal{R}$ is a small value that in this case

21 includes the conversions of energy to/from Kinetic energy (in diffusion and mechanical

22 generation), gravity wave drag, and a residual that results from maintaining energy balance in the

23 presence of numerical dissipation, each of which are also included in the output diagnostics 
1 (Suarez et al., 2010). The vertically integrated radiation term can be expanded to its top of the

2 atmosphere and surface boundary conditions:

$3\left[\frac{\partial H}{\partial t}\right]_{R A D}=\left(S W_{T}-S W_{S}\right)-\left(O L R+L W_{S}\right)$

The radiation term includes solar (net shortwave, SW, at the top of the atmosphere, $\mathrm{T}$,

5 and the surface, $S$ ) radiation, the net surface longwave radiation $\left(\mathrm{LW}_{\mathrm{S}}\right)$, and the outgoing $\mathrm{LW}$

6 radiation (OLR) at the top of the atmosphere. The MST term includes all the heating due to moist

7 processes, including the condensation heating and evaporation in all phases, and here, the

8 vertical integral of the MST term is the latent heat resulting from the production of precipitation.

9 The MERRA vertically integrated total water vapor $(w)$ budget for all phases can be

10 written as:

$11 \frac{\partial w}{\partial t}=-\nabla \cdot \overline{(\vec{V} w)}+(E-P)+\left[\frac{\partial w}{\partial t}\right]_{A N A}+F$

$12 w=\bar{q}_{v}+\bar{q}_{l}+\bar{q}_{i}$

13 The change of total water is related to the dynamical convergence of water, and the physical

14 processes of evaporation and precipitation (sum of convective, large-scale and frozen forms). In

15 the MERRA system, two non-physical terms affect the moisture budget. $F$ represents a very

16 small amount of negative filling, ensuring positive water vapor content. However, the ANA term

17 represents the analysis increment of water vapor, which is on the order of magnitude of $E-P$. As

18 MERRA system cycles in time, it performs a forecast, analysis, and then assimilation segment.

19 The assimilation segment is essentially a model forecast that includes the ANA or analysis

20 increment tendencies discussed previously. These budgets, and most MERRA output

21 diagnostics, are derived from the assimilation segment. A result of cycling the system in this way

22 is that the observational analysis tendencies can be quantified along-side the physical model data.

23 The result is that long term globally averaged water balances not just $\mathrm{E}$ and $\mathrm{P}$, but the analysis 
1 increment must be accounted for as well. The analysis increment is the forcing applied to a cycle

2 of the model simulation, developed from the analysis of observations and comparing the analysis

3 to a forecast cycle (Bloom et al. 1996). Additional information on the formulation of the budgets

4 is discussed by Rienecker et al (2007) and Suarez et al (2010).

5 3. Water and Energy Budgets

6 a. Climatology

TFK09 collect the global energy budget data from various sources, observational and

8 reanalyses, and close it with consistency arguments from data set intercomparisons, in order to

9 determine estimates for principal energy flux components and balance. However, each term

10 exhibits large variations among the different observing systems and reanalyses, so that any

11 determination of the global average energy budget still includes significant uncertainty. The

12 spatial and temporal variations then are that much more difficult to know with certainty. We will

13 characterize the MERRA global energy budget in terms of the existing data and analysis, to

14 identify those aspects which are realistic at global scales, with some further analysis of regional 15 scales.

16 Table 1 compares the results of the TFK09 evaluation of energy fluxes with MERRA

17 values during the same March 2000 to May 2004 period (see TFK09 for the values from other

18 reanalyses and observed data, their Table 2). At the top of the atmosphere, the MERRA net

19 radiative flux is slightly negative $\left(-0.2 \mathrm{~W} \mathrm{~m}^{-2}\right)$, which compares favorably with an adjusted

20 ISCCP estimate of $0.9 \mathrm{~W} \mathrm{~m}^{-2}$ warming (TFK09). We note that the current unadjusted CERES

21 TOA imbalance is in excess of $6 \mathrm{Wm}^{-2}$ (TFK09). The MERRA net flux is closer to the observed

22 estimates than the JRA-25 and NCEP-NCAR reanalyses. Comparing the TOA components of the

23 net radiation, MERRA OLR is larger than the TFK09 estimates (and also observations in their 
1 Figure 2) while the reflected shortwave radiation is underestimated, suggesting the effect of

2 clouds is weaker than expected. Similarly, at the surface, downward longwave radiation is 3 underestimated while the surface downward shortwave radiation is overestimated.

4 Since MERRA and the reanalyses considered in TFK09 use prescribed SST, the ocean

5 temperatures and heat content do not respond to the net downward flux at the ocean surface (for

6 example, $13.8 \mathrm{Wm}^{-2}$ in MERRA). While MERRA has a significant global average flux of heat

7 from the atmosphere to the ocean, the JRA surface flux sign is reversed (TFK09 Table 2). The

8 NCEP reanalysis shows little average net flux (TFK09, Table 2), especially over the oceans, but

9 at the expense of unrealistic solar reflection. A significant component of this difference between

10 MERRA and JRA is the ocean surface evaporation, where MERRA is much lower than JRA.

11 TFK09 (their Table 2) provides merged observation data from HOAPS and WHOI evaporation,

12 but a large discrepancy exists between them. This emphasizes the significant remaining

13 variations among reanalyses and recent satellite-based estimates. It is anticipated that the

14 emerging Seaflux data set (Clayson et al., 2010) will narrow the uncertainties for observed data

15 products. A similar conclusion can also be reached for land fluxes (Vinukollu et al. 2010), where

16 analyses fluxes are collectively biased and more variable than observed products.

18 b. Spatial variations

19 As discussed in the previous section, biases in cloud radiative effects plays a role in the

20 MERRA representation of the surface energy budget. Figure 1 compares the TOA longwave

21 cloud effect of MERRA to that computed from the SRB data set (Stackhouse et al. 2010).

22 Positive values indicate that MERRA cloud effect is weaker than SRB. So that, in MERRA, the

23 tropics have more cloud effect similar to the inter-America seas region (this tends toward boreal 
1 summer, not shown). On the other hand, extratropical regions have weaker cloud effect

2 (generally during the boreal winter, not shown). The center of the ITCZ in the eastern tropical

3 Pacific Ocean is also weaker in MERRA than SRB. The NCEP reanalyses show reasonable

4 comparison to the SRB data, except that the CFSR SPCZ has a notably weak bias. The ECMWF

5 and JRA reanalyses have generally weaker cloud effect everywhere. At this scale, high latitude

6 clouds and radiative effects are not apparent, but Cullather and Bosilovich (2010 a and b)

7 examine the high latitude water and energy budgets.

8 A distinctive feature of the MERRA global comparisons in the previous section is the

9 surface evaporation, especially over the ocean. Where most reanalyses show higher than merged

10 observation oceanic evaporation, MERRA is lower. Figure 2 shows the surface evaporation

11 comparison to the WHOI OAFLUX data set (Yu and Weller, 2007). The MERRA low bias is

12 generally related to extratropical evaporation near the warm western boundary current regions.

13 The MERRA field has a very strong gradient around the evaporation related to the warm

14 currents, and the feature is generally smaller scale than in OAFLX (not shown) so that the

15 underestimate in the maximum evaporation near the warm currents may be more related to the

16 differing spatial scales of the data. Away from the warm currents and near the high biases in the

17 tropical eastern Pacific Ocean, MERRA appears just generally lower than other reanalyses,

18 which consistently overestimate ocean evaporation to varying degrees.

19 Figure 3 shows the seasonal precipitation comparison among MERRA and other 20 reanalyses with GPCP (version 2.0 Adler et al., 2003) merged precipitation data. For MERRA,

21 the tropics precipitation tends to be overestimated, with the midlatitudes underestimated, which

22 is typical among reanalyses. MERRA's tropical bias, though, is less than the other reanalyses.

23 Many of the precipitation biases apparent here, are also consistent with the biases noted in 
1 comparing MERRA and TOA longwave cloud effect (Figure 1). For example, in the IAS and

2 tropical western Pacific regions where the MERRA cloud effect exceeds SRB, the precipitation

3 is overestimated. Likewise in the southern midlatitudes, MERRA precipitation is slightly

4 underestimated where the cloud effect is weaker. Reanalyses have been shown to be internally

5 consistent in terms of cloud-radiation anomalies (i.e. low cloud leads to high OLR), while

6 differences among the various reanalyses can be substantial (Newman et al., 2000). Several

7 continental regions' precipitation are underestimated compared to GPCP, especially South 8 America.

9 While MERRA mean precipitation biases are reasonable when compared to GPCP and

10 other reanalyses (as in Table 1), Figure 4 shows the spatial variability and ultimately the skill of

11 several global reanalyses to reproduce the annual mean distribution of precipitation relative to

12 GPCP in Taylor diagrams (Taylor 2001; Bosilovich et al. 2008). On these charts, CMAP

13 provides a secondary reference and sense of the observational uncertainty. Distance from the 1,1

14 point represents skill relative to the reference data set (GPCP in this comparison). In the global

15 comparison, MERRA and ERA Interim are the closest to GPCP and CMAP, but both also tend to

16 be more clustered together (smaller interannual variations of the statistics). CFSR also stands out

17 ahead of the former generation, though the variance tends to be higher than the current

18 generation of reanalyses. The global quality in MERRA and Interim can be attributed to the

19 improvements over ocean regions, but especially the tropical oceans. Figure 5 shows the time

20 series of the correlation and standard deviation values used to produce the Taylor diagram for the

21 Globe and Tropics (15S-15N), as well as the mean bias between the reanalyses and GPCP. While

22 MERRA has the lowest biases in the tropics and in the group of low bias for the globe, it has an

23 increasing trend relative to GPCP. On the other hand, ERA Interim's high bias in precipitation 
1 tends to decrease in time. MERRA tropical spatial correlations are higher than any older

2 reanalysis and comparable to ERA Interim and CFSR. JRA shows a strong change in

3 precipitation correlation as SSM/I data becomes increasingly available (see also Onogi et al.

4 2005). The MERRA standard deviation indicates that the variance across the tropics is

5 comparable to GPCP (which can also be said for NCEP Reanalysis 1 and Interim). The

6 representation of tropical precipitation in MERRA is much more comparable to GPCP than any

7 the older reanalyses. At these large scales, the similarity in statistical comparison of MERRA and

8 Interim with GPCP is remarkable. In the next section, we will evaluate the MERRA time series

9 of the energy and water budget terms.

10 4. Time Series

11 a. Interannual Variability

12 Previous research has shown that low frequency variability and trends in reanalyses are

13 problematic and should be considered very carefully. While some fields in certain regions may

14 be useful indicators of trends (Kalnay and Cai, 2003), there are numerous examples of artifacts

15 dominating real physical trends from reanalysis data. For example, ERA-40 precipitation has

16 strong decadal trends and interannual variability of tropical precipitation that do not appear in

17 observations (Uppala et al. 2005; Andersson et al. 2005). Likewise, JRA-25 precipitation

18 exhibits a stepwise shift when SSM/I retrieved total column water becomes available for

19 assimilation (Onogi et al. 2005). In this section, we are evaluating the full time series of MERRA

20 as an extension to the 5-year global climatological averages of the energy budget (in the previous

21 section) and to characterize the system as it changes in time.

22 The increasing trend in MERRA precipitation bias noted in Figure 5 is separated into

23 global, land and ocean components in Figure 6a. Precipitation over continental regions shows 
1 some periods of increase, but the global precipitation time series trends correlate more to the

2 precipitation over ocean. However, the oceanic trend is not linear, and undergoes a strong

3 transition period in the late 1990s. Globally and annually integrating the water budget (equation

4 3), the precipitation is balanced both by evaporation and the analysis increment of water vapor.

5 Some time variations apparent in global precipitation have similarities in both evaporation and,

6 especially, the analysis increment (Figure 6b). For example, through the early portion of the time

7 series, evaporation is steadily increasing and exceeds precipitation by roughly $0.1 \mathrm{~mm} \mathrm{~d}^{-1}$ so that

8 the moisture increment is negative by a roughly similar amount. However, 1999 and 2001 each

9 show stepwise changes in the analysis increments, which are generally reflected in the

10 precipitation. Evaporation also responds to this change by decreasing in 1999, but responds only

11 very weakly in 2001. After 1999, the increments act as a moisture source when the new AMSU

12 instruments on NOAA-15 (Nov 1998) and NOAA-16 (Jan 2001) become available. Robertson et

13 al. (2010) discuss the role of the AMSU-A window channels on water vapor and the possible

14 bias correction uncertainties as the basis for the change in the water vapor increment.

15 Precipitation is clearly sensitive to the changing observing system since the moisture increment

16 changes propagate through the GEOS-5 moisture and radiative physics.

17 Figure 7 examines the extent of the effect of the satellite instrument changes on the

18 oceanic surface energy budget. The downwelling shortwave radiation (Figure 7) follows the

19 water vapor increments (Figure 6b) most closely. In general, the surface shortwave radiation is

20 decreasing in time while the downward surface longwave radiation is increasing, reflecting the

21 increasing water vapor and clouds (not shown). The net heating of the ocean surface decreases

22 substantially over the period with the smallest net heating occurring during the most modern part

23 of the satellite era (the lowest point occurs in 2001 where it increases steadily after then, Figure 
1 7). The downward trend in net flux to the ocean surface is almost $10 \mathrm{Wm}^{-2}$ over the 30 -year

2 period and if not accounted for could cause significant problems if used for ocean model forcing.

3 While downwelling shortwave radiation shows a distinct series of changes much like the water

4 vapor increments or precipitation, the net ocean flux varies more slowly without the sharp

5 transitions, owing to the combined influences of the surface fluxes.

6 Figure 8 separates the net radiative flux contributions by LW and SW components at the 7 surface and top of the atmosphere. The surface net shortwave radiation variations exhibit the 8 jumps in the times series much like the analysis increments, with the surface longwave radiation 9 changing in the opposite direction and with smaller amplitude. Likewise, the TOA net shortwave 10 radiation has much the same variability as surface; both change from positive to negative when 11 AMSU is being assimilated (Figure 8) as cloud effects accompanying precipitation increases 12 reflection. In the global average, model simulated precipitation heating would be nearly balanced 13 between the net radiative flux divergence between the TOA and surface. However, for the 14 reanalysis in the presence of data assimilation, the heating increments must also be considered.

15 Figure 9 shows the analysis increment of heat in the atmosphere (dHdtANA). This forcing in the 16 global energy budget is $\sim 18 \mathrm{~W} \mathrm{~m}^{-2}$ in the early part of the period, when satellite observations are

17 less abundant. After 1998, the heating increments are much lower, $\sim 6 \mathrm{~W} \mathrm{~m}^{-2}$, but clearly 18 sensitive to the availability of AMSU. The other striking point of Figure 9 is the strong negative 19 correlation between the heating increment, and the vertically integrated latent heating (and so the 20 precipitation) in the atmosphere. Figure $6 \mathrm{~b}$ shows the water vapor increments (in units of $\mathrm{mm}$

$21 \mathrm{day}^{-1}$ ), so that there is a strong relationship between the global mean heating increments, water 22 vapor increments and precipitation. The magnitude of the response to AMSU in atmospheric 
1 latent heating and heating increment is $\sim 8 \mathrm{~W} \mathrm{~m}^{-2}$, while the net radiation (surface or TOA) is $\sim 2$ -

$2 \quad 3 \mathrm{~W} \mathrm{~m}^{-2}$.

3 Figure 6 indicates that the direct effects of the new observations are more consistently

4 present over the oceans. So that, the possibility exists that these sharp changes could affect the

5 continental regions through indirect effects, such as moisture transport. Fasullo and Trenberth

6 (2008a and b) and Trenberth et al. (2009) partition the water and energy budgets (respectively)

7 into land and ocean components to compute the transport from land to ocean. Table 2 provides

8 this partitioning for the MERRA water and energy budgets, and solving for the transport. A

9 fundamental difference from the previously cited calculations is the presence of the analysis

10 increments in the MERRA budgets. Note that the net radiative fluxes are residuals of very large

11 component flux values. The analysis increments are easily as large as the net radiative fluxes or

12 the P-E. Considering that the increments represent a corrective tendency accounting for much of

13 the mean error of the water state at any given time, the magnitude of these terms in the MERRA

14 budgets is quite large and they cannot be neglected.

15 For energy, the top of the atmosphere and land surface fluxes appear comparable to the

16 Fasullo and Trenberth (2008a) estimates. The large downward surface flux over the ocean

17 mentioned previously is quite apparent in the energy budget, and is likely influencing the ocean-

18 land energy transport (the sign of the flux is opposite to that computed by Fasullo and Trenberth,

19 2008a). We noted earlier that the imbalance of energy in the JRA-25 ocean radiation is about the

20 same magnitude as MERRA, but opposite in sign so that different reanalyses could manifest

21 different water and energy transport characteristics. For the global water budget, the moisture

22 transport value is generally comparable to that diagnosed by Trenberth et al (2007), and the

23 magnitudes of the increments are smaller than even the long term average of P-E. This seems 
1 reasonable for a long term average, but the temporal variations during the period also need to be

2 considered.

3 Given the significant extent of the observing system impact on oceanic radiative and

4 water fluxes, we also computed the time variation of the transport of water and energy between

5 the ocean and continental areas. Figure $10(a$ and $b$ ) show the anomalies of water budget terms

6 for ocean and continental areas, including the moisture transport between them. The shift of the

7 oceanic water vapor increments is comparable to that of the precipitation. The oceanic water

8 vapor transport becomes more negative after 1999, indicating more water vapor leaving the

9 oceanic areas, however, the magnitude of that change is much less than that of the water vapor

10 increments. On the other hand, for the continental water budgets the variations in precipitation

11 are much more closely related to the water vapor transport than the increments (Figure $10 \mathrm{~b}$ ).

12 The latter is the negative of the ocean transport scaled by land fraction. The heating of the

13 atmosphere due to the additional water analysis increment is a substantial term in the oceanic

14 area of the atmospheric heat budget (Figure 10c). However, the variability of this the water term

15 is nearly opposite of the heating analysis increment, so that when the moisture increment

16 increases dramatically in 1999 , the heating increment decreases. Here, the heat transport is the

17 sum of all heat transports, including enthalpy, kinetic energy and latent. In this area integration

18 then, the total transport of heat in Figure $10 \mathrm{c}$ and $\mathrm{d}$ does not show a transition in 1999, nor do

19 any of the component energy transports (not shown). This is also evident in the continental

20 energy budget, where the increments themselves do not change drastically, but rather, are fairly

21 steady demonstrating interannual variability anti-correlated to the total heat transport (Figure

22 10d). For the whole 30-y period then the land energy budget values are close to those given in

23 Table 1. In contrast to TFK09 these results indicate a weak export of energy from land to ocean 
1 and a persistent net TOA loss. These losses must be offset by the heating increment to maintain

2 agreement in temperature and moisture with observations. From a global perspective, this

3 underscores the fact that the effect of the transition to ATOVS is primarily over the ocean, with

4 intermittent changes over land occurring though transport processes.

5 b. Spatial Patterns of Satellite Instrument Change

6 The previous section shows that in the global average sense, that water vapor and heating

7 increments change noticeably with the availability of new radiance data (Figure $6 \mathrm{~b}$ and Figure

8 10a). The onset of AMSU data availability demarcates distinct climate regimes, from an energy

9 and water balance point of view. This is especially apparent in the water budget where the

10 globally averaged water vapor analysis increment changes sign. However, this does not provide

11 more specific information about what regions are affected by the change.

12 In order to get a sense of the large scale affect of this change in the observing system, we

13 compare short time averages from before and after the start of AMSU. Decadal time averages

14 from before AMSU (1990-97) are subtracted from time averages after (2000-08). This may

15 include some real variations in the observed record, but the previous analysis suggests that the 16 analysis increment change (observation system) is the globally dominant factor. Figure 11 shows

17 the change of the water budget component tendencies and fluxes. Precipitation increases in 18 many places especially in the southern hemisphere midlatitudes, and also in the tropics and

19 South Pacific Convergence Zone (SPCZ). The increases in precipitation generally correspond to

20 the locations of changes in the analysis increments, for example, in the southern hemisphere

21 midlatitudes. However, the SPCZ analysis increments seem smaller than the change in SPCZ

22 precipitation, but there appears to be an increase in moisture convergence there, so that the large-

23 scale circulation has also changed significantly, as there is less convergence (more divergence) in 
1 the eastern tropical pacific. The changes in evaporation are smaller than the other terms (note the

2 different contour levels), likely owing to the constraints of prescribed sea surface temperature

3 and assimilated near surface wind observations. However, the evaporation decreases in the

4 southern hemisphere midlatitudes where the increased moisture increments have likely decreased

5 the near-surface humidity deficit in the bulk aerodynamic evaporation term. The increased

6 atmospheric water vapor has increased the cloudiness, reducing shortwave radiation (increasing

7 longwave radiation) at the surface.

8 Figure 12 shows the effect of the AMSU instrument change on the atmospheric dry static

9 energy budget terms. TOA net (downward) radiation is consistently lower in the presence of

10 AMSU, driven less by OLR than by increasing reflected shortwave radiation due to increased

11 clouds. The direct effect of heating increments on the radiation components is systematic with

12 TOA net decreases over persistently cloudy eastern ocean basins, high latitude storm tracks, and

13 much of Africa. The changes in the analysis increments of heat are quite variable over

14 continental regions, but they appear to be balanced solely by the vertically integrated heat

15 convergence and release of total potential energy. At the surface, energy losses dominate over

16 ocean regions except in the Southern Ocean where latent heat flux has decreased. However, the

17 atmosphere also reacts by redistributing the energy dynamically by transport (note the difference

18 in contour intervals in each panel), consistent with the time series data presented in Figure 10.

19 This may also hold over the oceanic basins as well, except that there is imbalance of energy due

20 to prescribed SSTs, whereas the land model balances energy over the continental surfaces. The

21 effect of the AMSU generally reaches all of the water and energy components over oceans,

22 especially the warm pool and southern hemisphere midlatitudes, and so these regions will have 
1 features related to the changing observing system in the long time series. In a companion effort,

2 Robertson et al. (2010) diagnose these satellite sensor effects in more detail.

3 In the analysis presented thus far, there appears a widespread systematic change with

4 time of the water cycle components (Figure 11) over the oceans, but more subtle apparent effects

5 over the continents. However, the tropical continental regions do show some variations, and here

6 we consider the anomalies in the Amazon River basin and central Africa. Figure 13 shows the

7 time series of root zone soil water for the Amazon River basin (the area is similar to that used in

8 Bosilovich and Chern, 2006, their Figure 1). In conjunction with the start of AMSU

9 instrumentation, the soil water becomes systematically higher than in previous years, which

10 agrees with the increase in precipitation noted in Figure 11a. Figure 14 compares the mean

11 annual cycle of precipitation in the Amazon Basin before and after the start of AMSU for both

12 GPCP merged gauge-satellite rain rate and that of MERRA. MERRA appears to have a low bias

13 before AMSU, mostly focused on the transition from dry to wet season. But after AMSU,

14 MERRA produces more precipitation than the observed data. The AMSU period (1999-2006)

15 has shifted phase compared to the earlier period, and also compared to observations. It

16 interesting to note that GPCP wet season precipitation in the later period is higher than the earlier

17 period, which may indicate that there is a real increase in the region. Nonetheless, the change in

18 MERRA is more likely the result of the changing observing systems, and its effect reaching the

19 large tropical river basin. Given that evaporation, moisture convergence and the water vapor

20 increments are also changing in time (Figure 11), a more thorough analysis of this region,

21 beyond the scope of the present study is planned.

In central Africa, a significant hydrologic anomaly occurs, and its sign contrasts the

23 general changes over the oceans and also over the Amazon River basin. In time, precipitation 
1 and evaporation are decreasing while the area becomes more divergent despite increasing

2 vertically integrated water vapor increments. Figure 15a shows the comparison of MERRA

3 precipitation with that of a station near the center of the low anomaly. MERRA precipitation is

4 fairly comparable to the local observations early in the reanalysis, but exhibits a sharp drop of

5 local precipitation in late-1995. Over the region, the area becomes warm and dry, with

6 precipitation less than observed.

7 Further investigation of MERRA's assimilated observations shows that a single

8 radiosonde station (Bangui, Station ID 64650) is present in the interior of the continent near the

9 anomaly, while additional stations are only available at the coasts during most of the period.

10 Figure $15 \mathrm{~b}$ shows the monthly mean time series of $850 \mathrm{mb}$ specific humidity anomalies from

11 Bangui, compared with MERRA monthly water vapor anomalies (grid point at $4.5^{\circ} \mathrm{N}, 18.667^{\circ} \mathrm{E}$ ).

12 The radiosonde station water vapor drops substantially in time with MERRA precipitation, but

13 we also see that MERRA's water vapor analysis tracks the observations. Since this is the only

14 nearby radiosonde and satellite data are not as prevalent over land, this station's observations

15 influence the area radiating out for several hundred kilometers. In time, the surface becomes dry

16 and warm following the unusually persistent low precipitation. Eventually the atmospheric

17 circulation is affected, and subsidence forms over the region, possibly related to the AMSU

18 observation, even further limiting the extent of the precipitation. The feature also appears in

19 operational analyses surface flux fields comparisons with remotely sensed merged flux data

20 (Vinukollo et al. 2010). Preliminary investigation in the documentation of this station indicates

21 that the ground station equipment was changed in the mid-1990s (Leopold Haimberger, personal

22 communication 16 September 2010). These results emphasize the continuing need for 
1 consideration of the input observations along side the reanalyses data to best interpret the

2 reanalysis results.

4 5. Summary and conclusions

The MERRA representation of the Earth's water and energy cycle climatology has

6 several advantages over existing reanalyses but also weaknesses that have affected past

7 reanalyses as well. The MERRA climatological precipitation field has a small global bias and

8 improved spatial correlation compared to the existing global reanalyses, especially across the

9 tropics, and is also very similar to the ECMWF Interim reanalysis in that regard. While

10 MERRA's spatial resolution is finer than many of the previous generation reanalyses, the

11 number of variables produced is extensive. For example, the systems budget equations are

12 represented entirely, and can be closed. This closure requires the analysis increment term, that

13 part of the budgets that allows the model to be influenced by observations. The analysis

14 increments play a crucial role in the present evaluation of the global water and energy cycles.

15 Characterization of the strengths and weaknesses requires consideration not only of the model

16 physical processes, but, as emphasized here, the nature of the evolving observational record.

17 Comparing MERRA global climate energy budgets with previous studies and

18 observations (e.g. TFK09), some consistent biases become apparent. Cloud effects and many of

19 the surface and TOA radiation components suggest that MERRA clouds are optically weaker

20 than reality (too few or too thin). This allows excessive shortwave radiation at the surface,

21 especially over oceans. Time series analysis shows a decreasing trend in the shortwave radiation

22 at the surface, which is a general improvement to the surface energy balance. However, the time

23 series also shows that major stepwise changes occur in MERRA, most notably in the oceanic 
1 precipitation. These changes are clearly tied to the analysis increment, and are concurrent with

2 the addition of new satellite instrumentation. This is not a new feature in reanalyses, as the JRA-

325 has a clear dependency on the availability of SSM/I, and CFSR and Interim also show

4 sensitivity precipitation around the time of NOAA 15 and 16 . Nonetheless, this identifies a

5 general limitation that must be addressed in future reanalyses.

6 The strongest shifts in MERRA's water and energy budgets coincide with the availability

7 of AMSU instruments in 1999 and 2001. A concurrent study shows strong evidence that the

8 sensitivity of the system is related to AMSU-A window channels (Robertson et al., 2010); here

9 we have assessed the broad impact on the water and energy budgets. The direct effect is largely

10 related to oceanic regions (especially the southern hemisphere mid-latitudes, tropical western

11 Pacific and Indian oceans), though dynamical transports are significant in linking forcing over

12 ocean to processes over land, but the effect is more pronounced in some regions than others. The

13 new data leads to more precipitation, total column water, and clouds, with less net radiation at

14 the surface and less net radiation leaving at the top of the atmosphere.

15 The changes in the state of the water balance over the ocean differ in important ways

16 from those over the land. The transport between land and ocean does not correlate with the

17 analysis increments over land. Rather, precipitation over land is linked most closely to transport

18 from the ocean. This suggests that satellite epoch changes (e.g. AMSU-A availability) do

19 indirectly affect MERRA water and energy balance over land through altered moisture and heat

20 transport, where variations over the Amazon River basin are indicative of this response. Even

21 so, the dominant data type over land, radiosondes, can strongly influence MERRA state

22 variables, physics quantities and the trends. This can be demonstrated in central Africa, where a

23 single station influences a large region's water and energy cycles. The observational inputs to 
1 reanalyses are quite sizable, and have improved demonstrably over the years. These iterations

2 are clarifying the uncertainties that still exist, as well as their origin in both model physics and in

3 the quality of the input data stream. It is important for individual researchers to be aware of

4 variations in the observing system in regards to the science objectives of their research. This also

5 emphasizes the need for continuing research, development and production of reanalyses.

7 Acknowledgments

8 MERRA was developed with support from the NASA Modeling, Analysis and Prediction

9 program. This study was supported by the NASA Energy and Water cycles Studies (NEWS)

10 program. The work also benefitted from thoughtful comments from the NEWS Modeling

11 working group and the NEWS Global Energy Climatology working group. Siegfried Schubert.

12 Kevin Trenberth and Paul Stackhouse also provided many thoughtful suggestions over the course

13 of this study. Russell Vose and Leopold Haimberger provided valuable insights and discussions

14 about the Bangui station.

\section{6. Appendix: Acronyms}

17 AIRS Atmospheric Infrared Sounder

18 AMSU Advanced Microwave Sounding Unit

19 CERES Cloud's and the Earth's Radiant Energy System

20 CFSR Climate Forecasting System Reanalysis

21 CMAP NOAA Climate Prediction Center (CPC) Merged Analysis of Precipitation

22 ECMWF European Centre for Medium Range Weather Forecasts

23 ERA ECWMF Reanalysis (40 year or Interim)

24 GEOS-5 Goddard Earth Observing System (Version 5)

25 GPCC Global Precipitation Climatology Centre

26 GPCP Global Precipitation Climatology Project

27 GSI Gridpoint Statistical Interpolation

28 HOAPS Hamburg Ocean Atmosphere Parameters and Fluxes from Satellite Data

29 IAS Inter-America Seas

30 IAU Incremental Analysis Update 
1 ISCCP International Satellite Cloud Climatology Project

2 ITCZ Intertropical Convergence Zone

3 JRA-25 Japanese 25 year reanalysis

4 LW Longwave

5 MERRA Modern Era Retrospective-analysis for Research and Applications

6 NASA National Aeronautics and Space Administration

7 NCAR National Centers for Atmospheric Research

8 NCEP National Center for Environmental Prediction

9 NOAA National Oceanic and Atmospheric Administration

10 NRA NCEP-NCAR reanalysis

11 OAFLUX Objectively Analyzed air-sea Fluxes

12 OLR Outgoing longwave radiation

13 PW Petawatt

14 SPCZ South Pacific Convergence Zone

15 SRB Surface Radiation Budget

16 SSM/I Special Sensor Microwave Imager

17 SST Sea Surface Temperature

18 TIROS Television Infrared Observation Satellite

19 TOA Top of atmosphere

20 TOVS TIROS Operational Vertical Sounder

21 WHOI Woods Hole Oceanographic Institution 


\section{References}

2 Adler, R. F., G. J. Huffman, GJ; A. Chang, and co-authors., 2003: The version-2 global precipitation climatology project (GPCP) monthly precipitation analysis (1979-present). J. Hydromet., 4, 1147-1167.

Andersson, E., P. Bauer, A. Beljaars, F. Chevallier, E. Hólm, M. Janisková, P. Kållberg, G. Kelly, P. Lopez, A. Mcnally, E. Moreau, A.J. Simmons, J.N. Thépaut, and A.M. Tompkins, 2005: Assimilation and Modeling of the Atmospheric Hydrological Cycle in the ECMWF Forecasting System. Bull. Amer. Meteor. Soc., 86, 387-402.

Bengtsson L, S. Hagemann and K. I. Hodges, 2004: Can climate trends be calculated from reanalysis data? J. Geophys Res., 109, D11111, doi:10.1029/2004JD004536

Bengtsson, L., and J. Shukla, 1988: Integration of space and in situ observations to study global climate change, Bull. Amer. Meteor. Soc., 69(10), 1130-1143.

Bosilovich, M. G. and J.-D. Chern, 2006: Simulation of Water Sources and Recycling for The MacKenzie, Mississippi and Amazon River Basins. J. Hydromet., 7, 312-329.

Bosilovich, M.G., and S.D. Schubert, 2001: Precipitation Recycling over the Central United States Diagnosed from the GEOS-1 Data Assimilation System. J. Hydrometeor., 2, 26-35.

Bosilovich, M.G., J. Chen, F.R. Robertson, and R.F. Adler, 2008: Evaluation of Global Precipitation in Reanalyses. J. Appl. Meteor. Climatol., 47, 2279-2299.

Bosilovich, M.G., D. Mocko, J.O. Roads, and A. Ruane, 2009: A Multimodel Analysis for the Coordinated Enhanced Observing Period (CEOP). J. Hydrometeor., 10, 912-934.

Bloom, S. C., L. L. Takacs, A. M. da Silva, and D. Ledvina, 1996: Data assimilation using incremental analysis updates. Mon. Wea. Rev., 124, 1256-1271.

Chen, J., A.D. Del Genio, B.E. Carlson, and M.G. Bosilovich, 2008a: The Spatiotemporal 
Structure of Twentieth-Century Climate Variations in Observations and Reanalyses. Part I: Long-Term Trend. J. Climate, 21, 2611-2633.

Chen, J., A.D. Del Genio, B.E. Carlson, and M.G. Bosilovich, 2008b: The Spatiotemporal Structure of Twentieth-Century Climate Variations in Observations and Reanalyses. Part II: Pacific Pan-Decadal Variability. J. Climate, 21, 2634-2650.

Cullather, R. I., and M. G. Bosilovich 2010a: The Moisture Budget of the Polar Atmosphere in MERRA. Submitted to the Journal of Climate MERRA Special Issue..

Cullather, R. I., and M. G. Bosilovich 2010b: The Energy Budget of the Polar Atmosphere in MERRA. Submitted to the Journal of Climate MERRA Special Issue.

Fasullo, J.T., and K.E. Trenberth, 2008a: The Annual Cycle of the Energy Budget. Part I: Global Mean and Land-Ocean Exchanges. J. Climate, 21, 2297-2312.

Fasullo, J.T., and K.E. Trenberth, 2008b: The Annual Cycle of the Energy Budget. Part II: Meridional Structures and Poleward Transports. J. Climate, 21, 2313-2325.

Kalnay, E. and co-authors, 1996: The NCEP/NCAR 40-Year Reanalysis Project. Bull. Amer. Meteor. Soc., 77, 437-431.

Kalnay E. and M. Cai, 2003: Impact of Urbanization and Land-use Change on Climate. Nature, $423,528-531$.

Kanamitsu, M., W. Ebisuzaki, J. Woollen, S-K Yang, J.J. Hnilo, M. Fiorino, and G. L. Potter, 2002: NCEP-DOE AMIP-II Reanalysis (R-2). Bull. Amer. Met. Soc., 83, 1631-1643.

Loeb, N.G., B.A. Wielicki, D.R. Doelling, G.L. Smith, D.F. Keyes, S. Kato, N. Manalo-Smith, and T. Wong, 2009: Toward Optimal Closure of the Earth's Top-of-Atmosphere Radiation Budget. J. Climate, 22, 748-766. 
1 Maurer, E. P., G. M. O'Donnell and D. P. Lettenmaier, 2001: Evaluation of the land surface water budget in NCEP/NCAR and NCEP/DOE reanalyses using an off-line hydrologic model. J. Geophys Res., 106, 17841-17862.

Newman, M., P. D. Sardeshmukh, J. W. Bergman, 2000: An Assessment of the NCEP, NASA, and ECMWF Reanalyses over the Tropical West Pacific Warm Pool. Bull. Amer. Meteror. Soc. 81, 41-48.

Onogi, K. and co-authors, 2005: JRA-25: Japanese 25-year re-analysis project-progress and status. Q. J. R. Meteorol. Soc. (2005), 131, 3259-3268.

Onogi, K. and co-authors, 2007: The JRA-25 Reanalysis. J. Met. Soc. Japan, 85, 369-432.

Rienecker, M.M.. M.J. Suarez, R. Todling, J. Bacmeister, L. Takacs, H.-C. Liu, W. Gu, M. Sienkiewicz, R.D. Koster, R. Gelaro, and I. Stajner, 2007: The GEOS-5 Data Assimilation System - Documentation of Versions 5.0.1 and 5.1.0. NASA GSFC Technical Report Series on Global Modeling and Data Assimilation, NASA/TM-2007104606, Vol. 27., pp. 92.

Rienecker, M. R. and co-authors, 2010: An overview of MERRA. In Preparation.

Roads J., and A. K. Betts, 2000: NCEP-NCAR and ECMWF Reanalysis Surface Water and Energy Budgets for the Mississippi River Basin. J. Hydromet. 1, 88-94.

Roads, J. O., M. Kanamitsu and R. Stewart, 2002: CSE Water and Energy Budgets in the NCEPDOE Reanalysis II. J. Hydromet., 3, 227-248.

Robertson, F. R., M. G. Bosilovich, J. Chen and T. L. Miller (2010): The Effect of Satellite Observing System Changes on MERRA Water and Energy Fluxes. Submitted to the Journal of Climate MERRA Special Issue. 
1 Saha, S., and Coauthors, 2010: The NCEP Climate Forecast System Reanalysis. Bull. Amer. Meteor. Soc., 91, 1015-1057.

3 Schlosser, C.A., Houser P.R., 2007: Assessing a Satellite-Era Perspective of the Global Water $4 \quad$ Cycle. J. Clim., 20, 1316-1338.

5 Schneider, U., T. Fuchs, A. Meyer-Christoffer and B. Rudolf, 2008: Global Precipitation Analysis Products of the GPCC. Global Precipitation Climatology Centre (GPCC), DWD, Internet Publikation, 1-12. (ftp://ftp-anon.dwd.de/pub/data/gpcc/PDF/GPCC_intro_products_2008.pdf)

Schubert, S. D., and Y. Chang, 1996: An objective method for inferring sources of model error. Mon. Wea. Rev., 124, 325-340.

Simmons, A., S. Uppala and D. Dee, 2007: Update on ERA-Interim. ECMWF Newsletter No. 111, pg. 5. [http://www.ecmwf.int/publications/newsletters/pdf/111.pdf]

Stackhouse, P.W., Jr., S. K. Gupta, S. J. Cox. T. Zhang, J.C. Mikovitz, and L. M. Hinkelman, 2010: A Long-term Estimate of the Earth's Surface Radiation Budget: The NASA/GEWEX Surface Radiation Budget Release 3.0 Dataset (in preparation).

Suarez, M. and co-authors, 2010: File Specification for MERRA Products. Global Modeling and Assimilation Office, Greenbelt MD. [http://gmao.gsfc.nasa.gov/research/merra/file_specifications.php]

Taylor, K. E., 2001: Summarizing multiple aspects of model performance in a single diagram. $J$. Geophys. Res., 106, D7, 7183-7192.

Trenberth, K.E., and J.G. Olson, 1988: An evaluation and intercomparison of global analyses from the National Meteorological Center and the European Centre for Medium Range Weather Forecasts. Bull. Amer. Meteor. Soc., 69(9), 1047-1057. 
1 Trenberth, K. E., L. Smith, T. Qian, A. Dai and J. Fasullo, 2007: Estimates of the Global Water Budget and Its Annual Cycle Using Observational and Model Data. J. Hydromet., 8, 758769.

4 Trenberth, K.E., J.T. Fasullo, and J. Kiehl, 2009: Earth's Global Energy Budget. Bull. Amer. Meteor. Soc., 90, 311-323.

6 Uppala, S. M., and co-authors, 2005: The ERA-40 re-analysis, QJRMS, 131 Part B, 2961-3012.

7 Uppala, S., D. Dee, S. Kobayashi, P. Berrisford, and A. Simmons, 2008: Towards a climate data assimilation system: status update of ERA-Interim. ECMWF Newsletter No. 115, 12-18. [http://www.ecmwf.int/publications/newsletters/pdf/115.pdf]

Vinukollu, R., J. Sheffield, E. F. Wood, M. G. Bosilovich and D. Mocko, 2010: Multi-model analysis of Energy and Water Fluxes: Intercomparisons between Operational Analyses, Land Surface Model and Remote Sensing, In Preparation.

Wu, W.-S., R.J. Purser and D.F. Parrish, 2002: Three-dimensional variational analysis with spatially inhomogeneous covariances. Mon. Wea. Rev., 130, 2905-2916.

Yu, L., and R.A. Weller, 2007: Objectively Analyzed Air-Sea Heat Fluxes for the Global IceFree Oceans (1981-2005). Bull. Amer. Meteor. Soc., 88, 527-539.

Xie P., and P.A. Arkin, 1996: Global precipitation: A 17-year monthly analysis based on gauge observations, satellite estimates, and numerical model outputs. Bull. Amer. Meteor. Soc., 78(11), 2539-2558. 
2 Table 1 Energy fluxes (March 2000 - May 2004) partitioned by Global, Global Land and Global

Ocean averages and compared to the estimates developed by TFK09. TFK09 also provide ISSCP-FD, NCEP reanalyses, JRA-25 and WHOI and HOAPS ocean fluxes for comparison.

a.) TOA

\begin{tabular}{|c|c|c|c|c|c|c|}
\hline Global & Solar In & Solar Refl & Albedo \% & Solar Net & OLR & NET down \\
\hline \begin{tabular}{|l|} 
MERRA \\
\end{tabular} & 341.3 & 99.6 & 29.2 & 241.7 & 242.0 & -0.2 \\
\hline TFK09 & 341.3 & 101.9 & 29.8 & 239.4 & 238.5 & 0.9 \\
\hline \multicolumn{7}{|l|}{ Land } \\
\hline MERRA & 325.7 & 106.8 & 32.8 & 218.9 & 232.9 & -14.0 \\
\hline TFK09 & 330.2 & 113.4 & $\overline{34.4}$ & 216.8 & 232.4 & -15.6 \\
\hline \multicolumn{7}{|l|}{ Ocean } \\
\hline MERRA & 347.9 & 96.6 & 27.8 & 251.2 & 245.7 & 5.5 \\
\hline TFK09 & 345.4 & 97.8 & 28.3 & 247.7 & 240.8 & 6.9 \\
\hline
\end{tabular}

b.) Surface

\begin{tabular}{|c|c|c|c|c|c|c|c|c|c|}
\hline Global & $\begin{array}{l}\text { Solar } \\
\text { Absorb }\end{array}$ & Solar Net & $\begin{array}{l}\text { Solar } \\
\text { reflect }\end{array}$ & LH & $\mathrm{SH}$ & LW Up & LW Down & Net LW & NET down \\
\hline MERRA & 72.7 & 169.1 & $\overline{23.6}$ & 76.4 & $\overline{18.3}$ & 394.3 & 330.3 & 64.0 & 9.4 \\
\hline TFK09 & 78.2 & 161.2 & 23.1 & 80.0 & 17.0 & 396.0 & 333.0 & 63.0 & 1.2 \\
\hline \multicolumn{10}{|l|}{ Land } \\
\hline MERRA & 68.7 & 150.2 & $\overline{46.7}$ & 44.9 & $\overline{33.2}$ & 364.6 & 294.6 & 70.0 & 2.0 \\
\hline TFK09 & 78.0 & 145.1 & 39.6 & 38.5 & 27.0 & 383.2 & 303.6 & 79.6 & 0.0 \\
\hline \multicolumn{10}{|l|}{ Ocean } \\
\hline \begin{tabular}{|l|} 
MERRA \\
\end{tabular} & 74.3 & 176.9 & 14.0 & 89.5 & 12.1 & 406.6 & 345.2 & 61.5 & 13.8 \\
\hline TFK09 & 78.2 & 167.8 & 16.6 & 97.2 & 12.0 & 400.8 & 343.2 & 57.6 & 1.3 \\
\hline
\end{tabular}


2 Table 2 The land and ocean water and energy budgets including transport (dwdtDYN and dHdtDYN) between land/ocean from MERRA 30 years average. The water budget terms are evaporation $(E)$, precipitation $(P)$, water vapor analysis increment (dwdtANA). The energy budget terms are net fluxes at the surface (SFC) and top of the atmosphere (TOA), analysis increment of dry static heat (dHdtANA) and heating of due to the analysis of water (dHdtANAw)

\begin{tabular}{|c|c|c|c|c|}
\hline & \multicolumn{4}{|c|}{ Water Budget $\left(\times 10^{3} \mathrm{Km}^{3} \mathrm{yr}^{-1}\right)$} \\
\hline & $\mathbf{E}$ & $\mathbf{P}$ & dwdtANA & dwdtDYN \\
\hline Land & 87 & 116 & -9 & 39 \\
\hline Ocean & 405 & 368 & 1 & -39 \\
\hline
\end{tabular}

Energy Budget (PW)

\begin{tabular}{|l|c|c|c|c|c|}
\hline \multicolumn{2}{c}{ SFC } & \multicolumn{1}{c}{ TOA } & \multicolumn{1}{c}{ dHdtANA } & \multicolumn{1}{c|}{ dHdtANAw } & dHdtDYN \\
\hline Land & -0.1 & -2.0 & 3.4 & -0.7 & -0.6 \\
\hline Ocean & -6.5 & 2.9 & 2.8 & 0.1 & 0.6 \\
\hline
\end{tabular}

8

9

10

11

\section{List of Figures}

Figure 1 Annual differences (1990-2002) of MERRA and other reanalyses longwave cloud effect from that of the Surface Radiation Budget (SRB) data. Here, the longwave effect is the TOA all-sky outgoing longwave radiation (OLR) minus the clear-sky outgoing longwave radiation, so that positive difference indicates the reanalysis cloud effect is less than SRB. There global area average of each map is included in the upper right corner of each panel. Additional figures are available from The MERRA Atlas (GMAO, 2010). 
1 Figure 2 Annual differences (1990-2002) between MERRA and other reanalyses ocean surface latent heat flux and that of OAFLUX merged data (Weller and Yu, 2007). Positive flux is directed upward.

4 Figure 3 Annual differences (1990-2002) between MERRA and other reanalyses precipitation with GPCP merged data (Adler et al. 2003).

Figure 6 Global annual averages of (a) precipitation including land-only and ocean only averages, and (b) the global annual averages of the water budget including precipitation (P), evaporation (E) and analysis increment of water vapor (Qvinc).

Figure 7 Global ocean-only (a) annual anomalies for surface energy budget terms latent heat flux (-LE), sensible heat flux (-Hs), downward shortwave radiation (SWdn) and downward longwave radiation (LWdn) and (b) annual mean Net downward flux at the ocean 
surface. The mean values of the terms are oriented positive down to the surface. Mean values of the anomalies are included in the legend. Units are $\mathrm{W} \mathrm{m}^{-2}$.

Figure 8 Global annual anomalies for (a) net radiation terms at the surface, shortwave (SWnet), longwave (LWnet) and the Net Radiation, (b) surface heat fluxes (positive down) including the Net heating and (c) radiation terms at the top of the atmosphere (TOA) net shortwave radiation (SWnet), upward longwave (LWup) and net top of atmosphere radiation (TOAnet). The means for each term are included in the legends. Units are in W $\mathrm{m}^{-2}$.

Figure 9 Energy terms for the moist processes (MST, essentially latent heating due to precipitation) and the heating due to analysis increments. Units in $\mathrm{Wm}^{-2}$.

Figure 10 Separate terms for the integrated water mass and energy budgets over land and ocean to compute land-ocean transport (a) ocean water budget anomalies, (b) continental budget (see table 2 for the time means and variable definitions), (c) oceanic energy terms and (d) land energy terms.

Figure 11 Change (2000-08 minus 1990-97, after AMSU minus before) of the atmospheric hydrology budget terms Precipitation (a), Evaporation (b) Incremental Analysis Update for water vapor (c) and moisture convergence (d). The change of evaporation is smaller than other terms and is scaled different from other terms.

Figure 12 Change (2000-08 minus 1990-97, after AMSU minus before) of the atmospheric energy budget terms Net TOA radiation (a) Net Surface Energy Flux (b), Incremental Analysis Update for dry static heat (c) and heat convergence. 
1 Figure 13 Time series of MERRA monthly mean root zone soil wetness fraction (nondimensional), area averaged over the Amazon River basin.

3 Figure 14 Mean annual cycle of monthly precipitation Area averaged over the Amazon River 4 basin from MERRA before AMSU data (1979-1998, dashed line) and MERAA when AMSU data is assimilated (1999-2006), solid line, and also the corresponding GPCP (Adler et al. 2003) basin averaged precipitation ( $\bullet$ for $1979-1998$, and $\boldsymbol{\Delta}$ for $1999-$ 2006). Units are $m m$ day $^{-1}$.

Figure 15 Time series of monthly MERRA data compared to observations at the MERRA point $\left(4.5^{\circ} \mathrm{N}, 18.67^{\circ} \mathrm{E}\right)$. (a) GPCC precipitation (dots with thin line; Schneider et al. 2008) and MERRA precipitation (thick solid line) and (b) Bangui radiosonde observations (dots, station ID $64650,4.24^{\circ} \mathrm{N}, 18.31^{\circ} \mathrm{E}$ ) of $850 \mathrm{mb}$ specific humidity anomaly compared to MERRA. The anomalies were calculated by removing the mean annual cycle. 


\section{Figures}

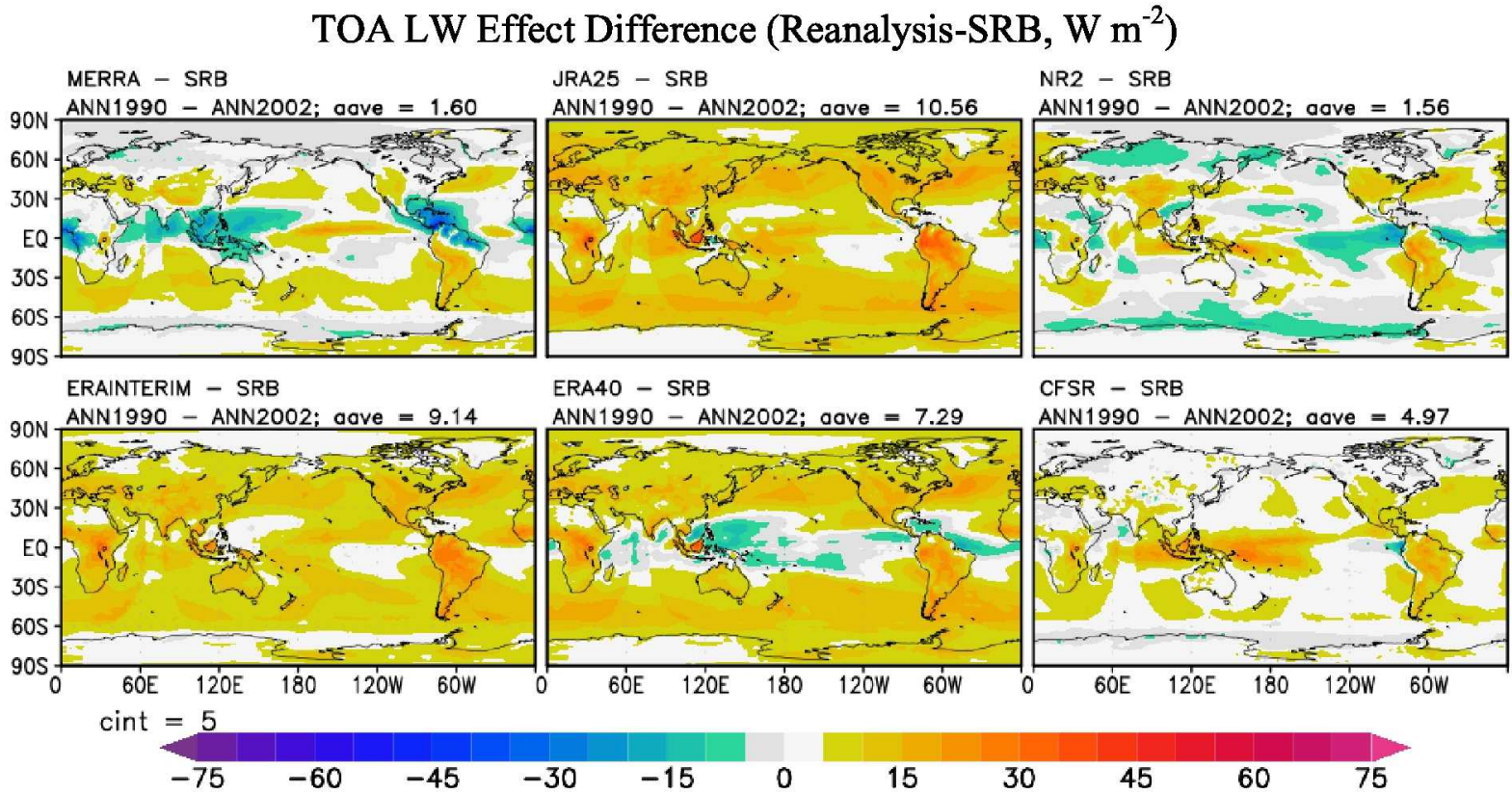

5 Figure 1 Annual differences (1990-2002) of MERRA and other reanalyses longwave cloud effect

6 from that of the Surface Radiation Budget (SRB) data. Here, the longwave effect is the TOA all-

7 sky outgoing longwave radiation (OLR) minus the clear-sky outgoing longwave radiation, so

8 that positive difference indicates the reanalysis cloud effect is less than SRB. 
Latent Heat Flux Difference (Reanalysis-OAFLUX W m ${ }^{-2}$ )

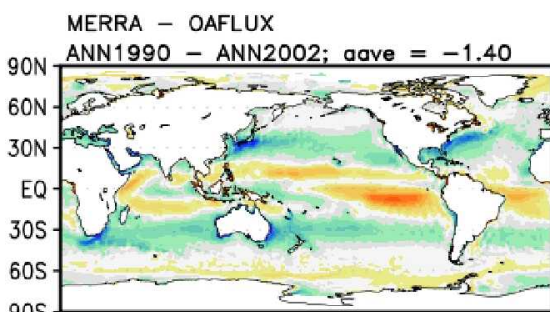

JRA25 - OAFLUX

ANN1990 - ANN2002; adve $=17.21$

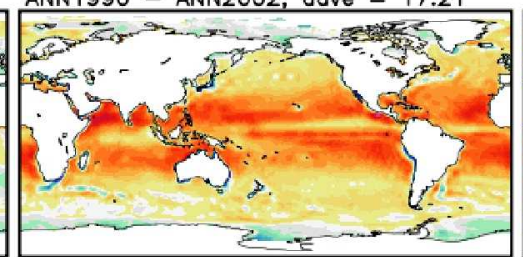

ERAINTERIM - OAFLUX

$90 N$ ANN1990 - ANN2002; aave $=8.37$

$60 N$ -

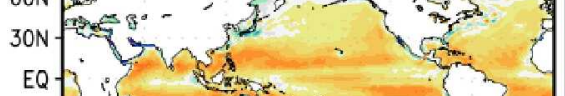

$305-30$ by

905

$905+$

ERA40 - OAFLUX

$\operatorname{cin} t=5$

NR2 - OAFLUX

ANN1990 - ANN2002; aave $=16.76$

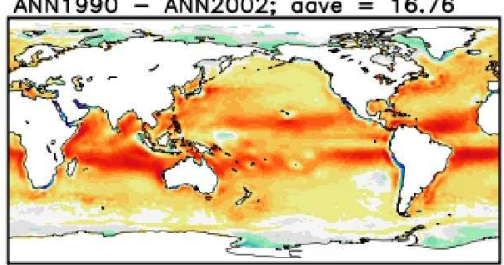

ANN1990- CFSR - OAFLUX

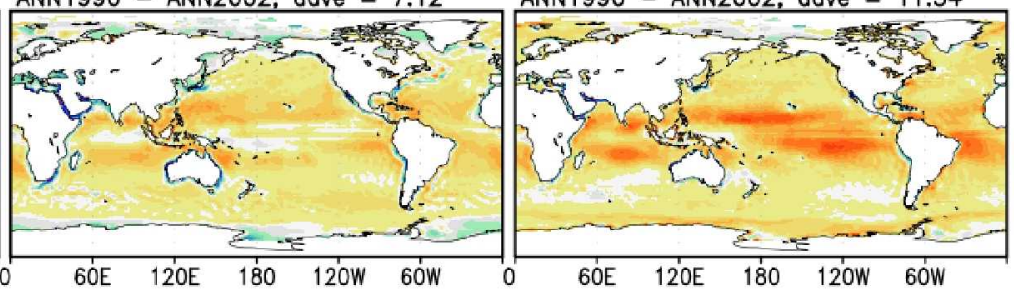

ANN1990 - ANN2002; aave $=11.34$

1

$\begin{array}{lllll}-75 & -60 & -45 & -30 & -15\end{array}$

15

30

45

$60 \quad 75$

2 Figure 2 Annual differences (1990-2002) between MERRA and other reanalyses ocean surface

3 latent heat flux and that of OAFLUX merged data (Weller and Yu, 2007). 


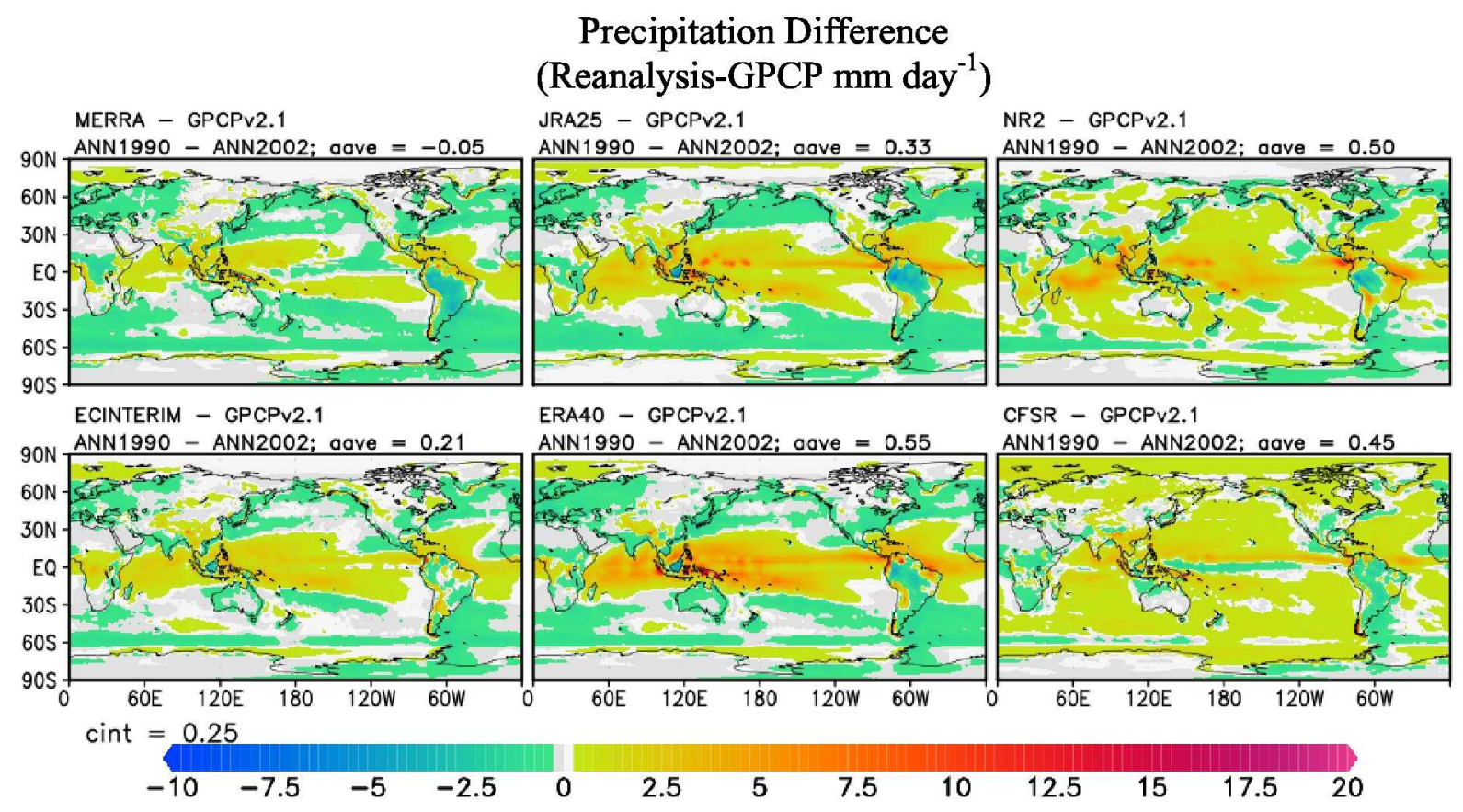

3 Figure 3 Annual differences (1990-2002) between MERRA and other reanalyses precipitation

4 with GPCP merged data (Adler et al. 2003). 
1

Global

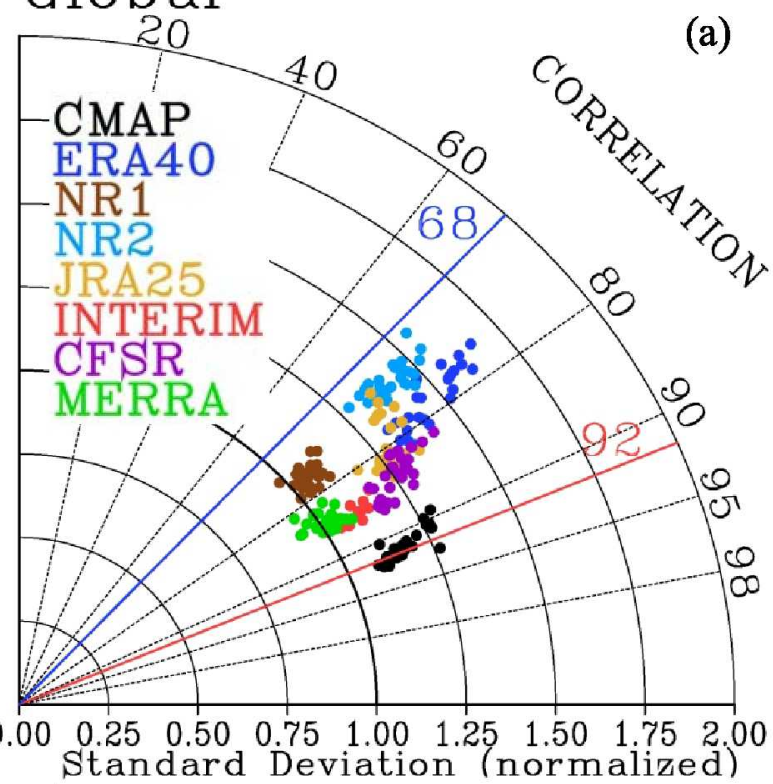

2

Global Ocean

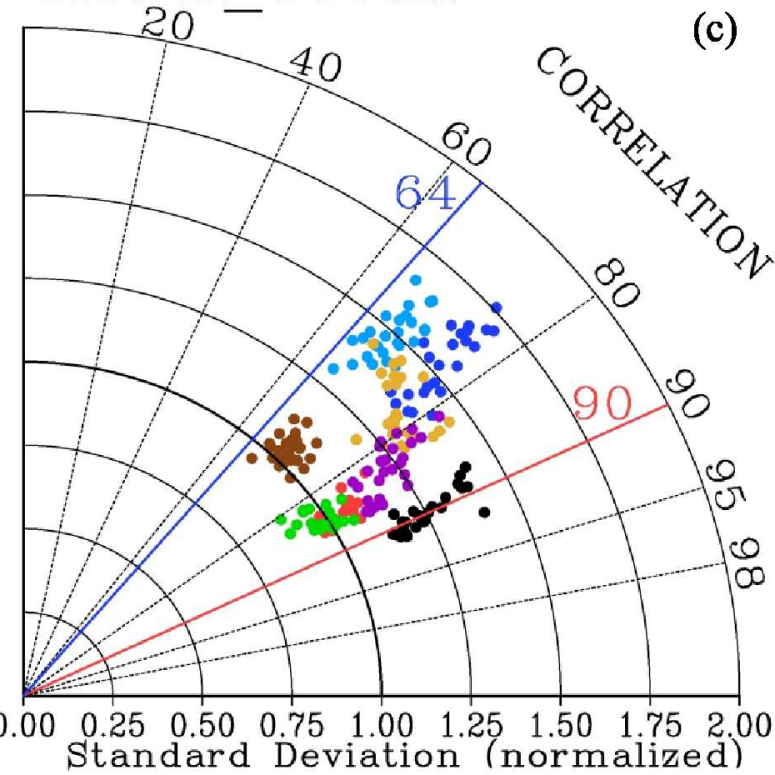

Global_Land

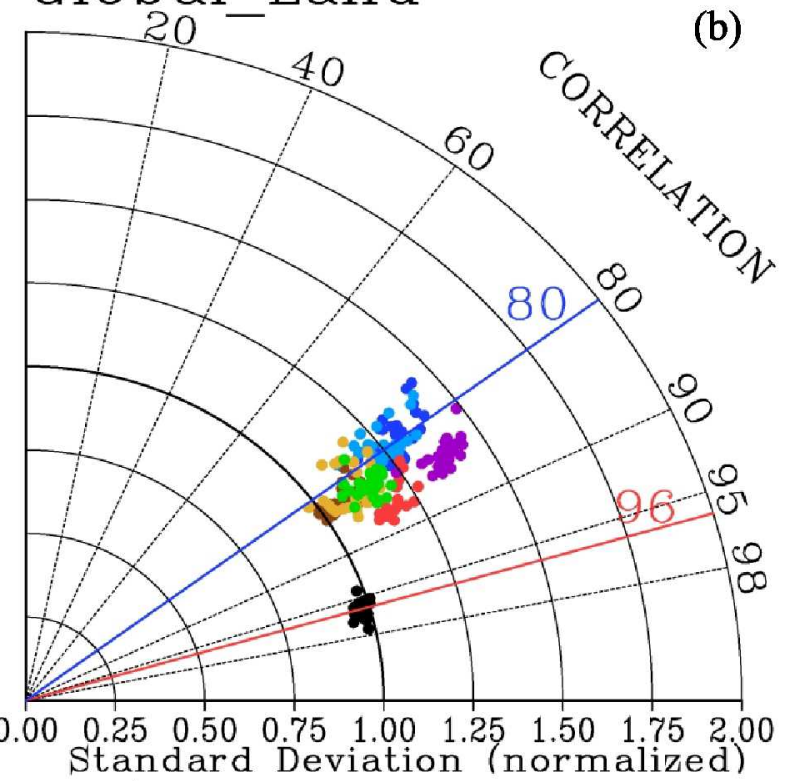

$15 \mathrm{~S}-15 \mathrm{~N}$ Latitude

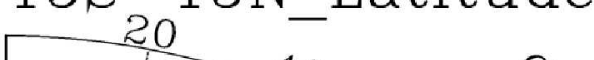

(d)

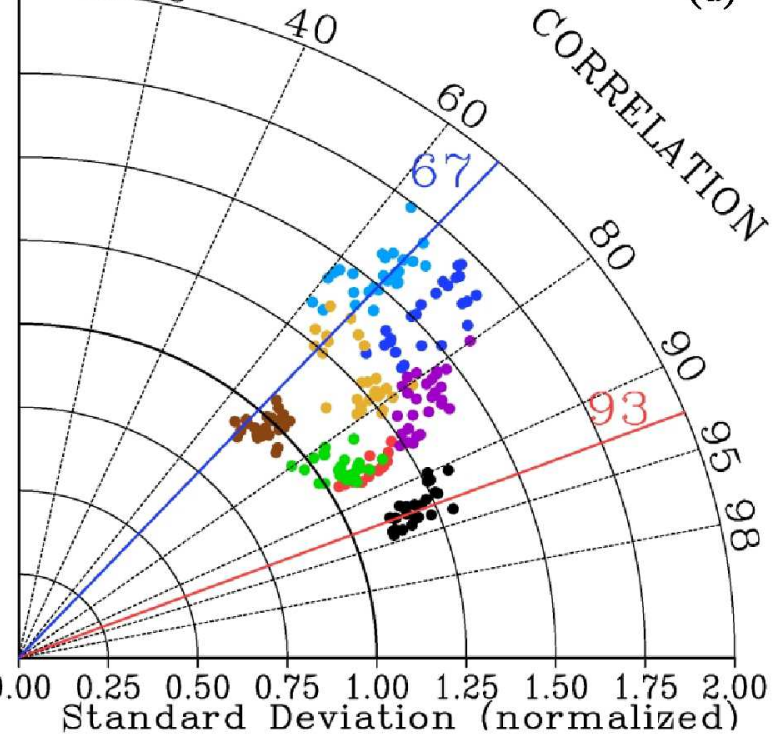

Figure 4 Taylor diagrams of annual mean precipitation from reanalyses using GPCP as a reference and CMAP as an additional observing reference. Each panel shows the statistics for

6 different regions: (a) globe, (b) land, (c) ocean and (d) tropics. The red and blue lines show limits

7 of expected high and low correlation as determined by comparing GPCP and CMAP 8 observations. See Bosilovich et al (2008) for details. 
1
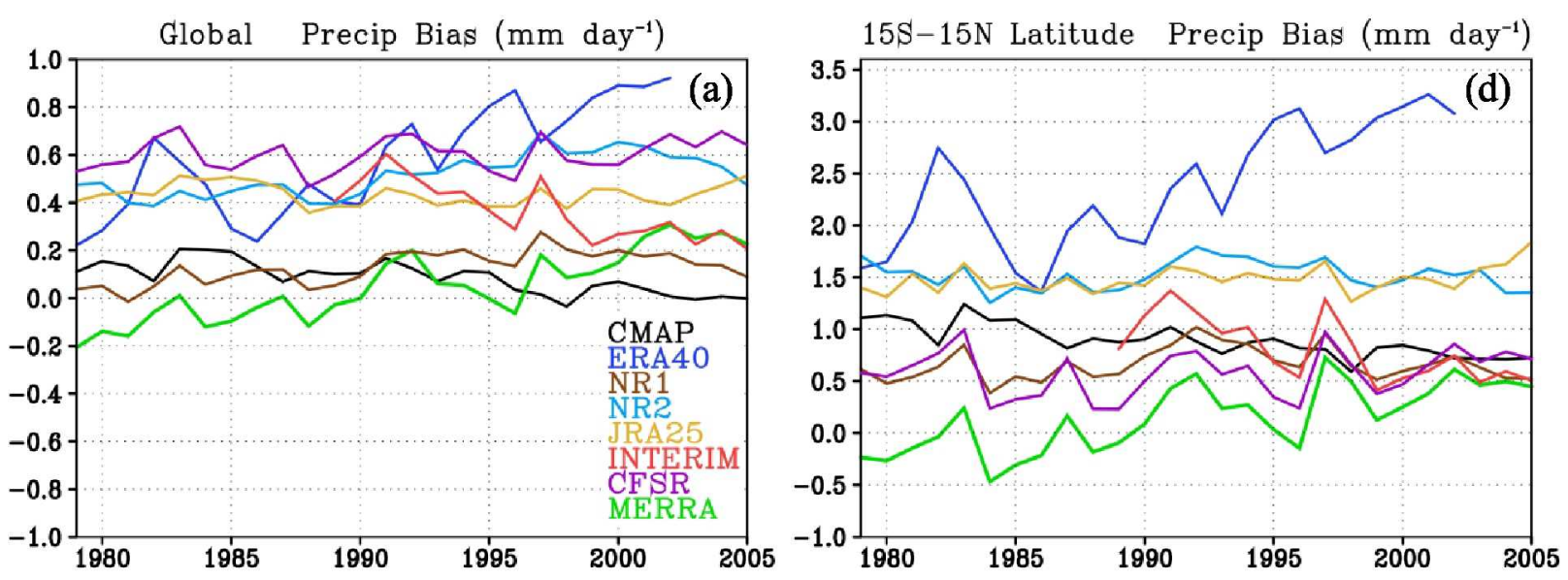

3
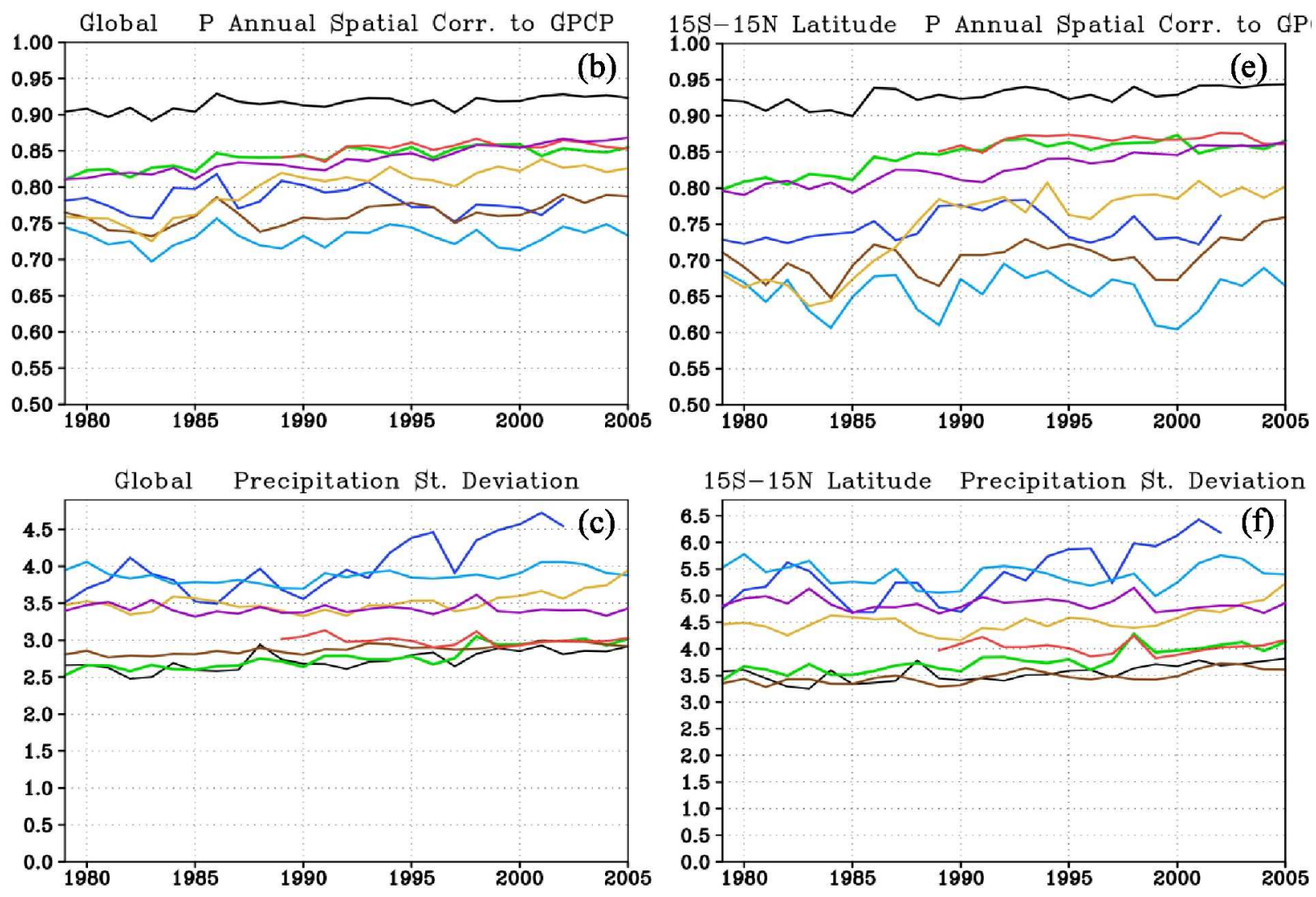

Figure 5 Time series of annual mean statistics used in the global (a-c) and tropics (d-f) Taylor diagrams (Figure $4 \mathrm{a}, \mathrm{d})$ for $(\mathrm{a}, \mathrm{d})$ mean difference form GPCP, $(\mathrm{b}, \mathrm{e})$ spatial correlation to GPCP and (c,f) standard deviation (here the black line is GPCP standard deviation, while the Taylor diagrams are normalized to GPCP standard deviation). 


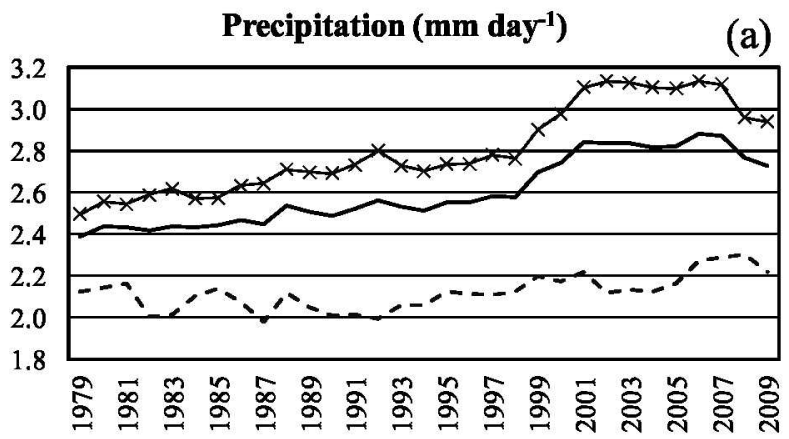

-Global - - Land $*$ Ocean

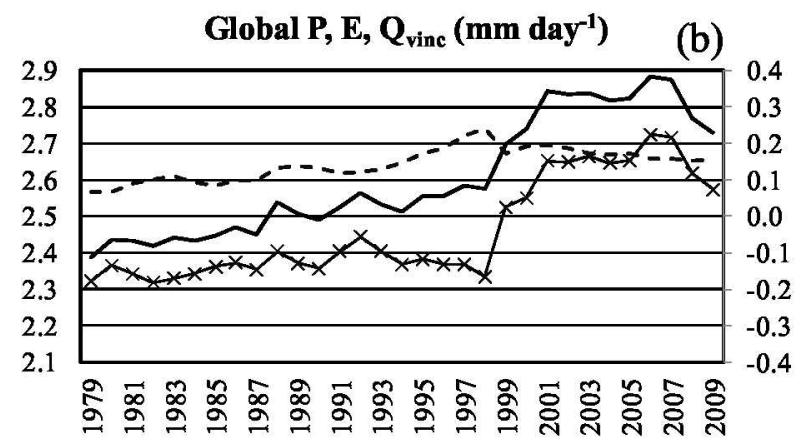

3

4

Figure 6 Global annual averages of (a) precipitation including land-only and ocean only averages, and (b) the global annual averages of the water budget including precipitation (P), evaporation (E) and analysis increment of water vapor (Qvinc).
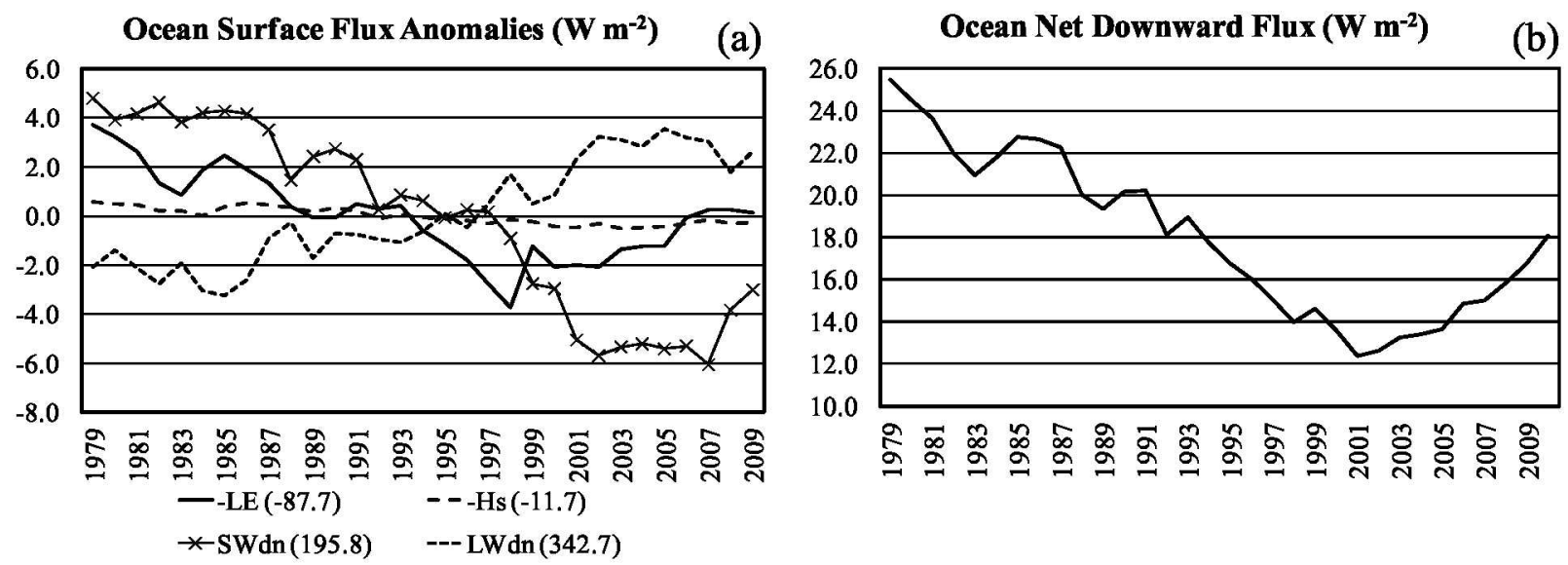

8

Figure 7 Global ocean-only (a) annual anomalies for surface energy budget terms latent heat flux (-LE), sensible heat flux (-Hs), downward shortwave radiation (SWdn) and downward longwave radiation (LWdn) and (b) annual mean Net downward flux at the ocean surface. 


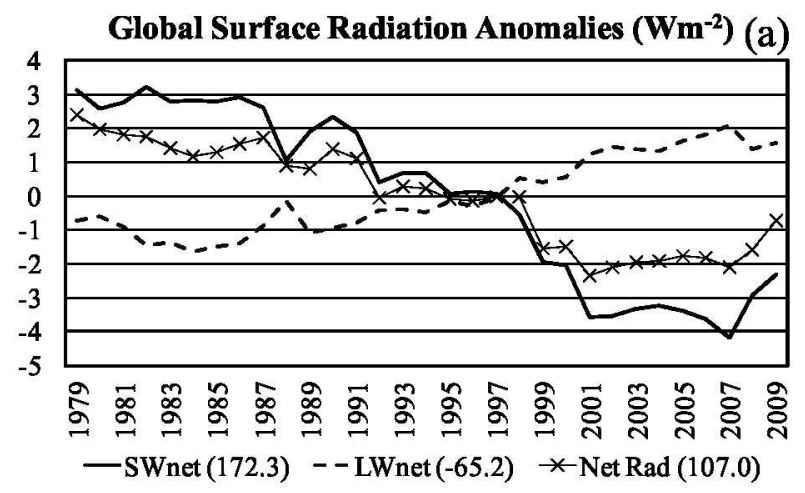

1

Global Surface Heat Flux Anomalies $\left(\mathbf{W m}^{-2}\right)(\mathrm{b})$

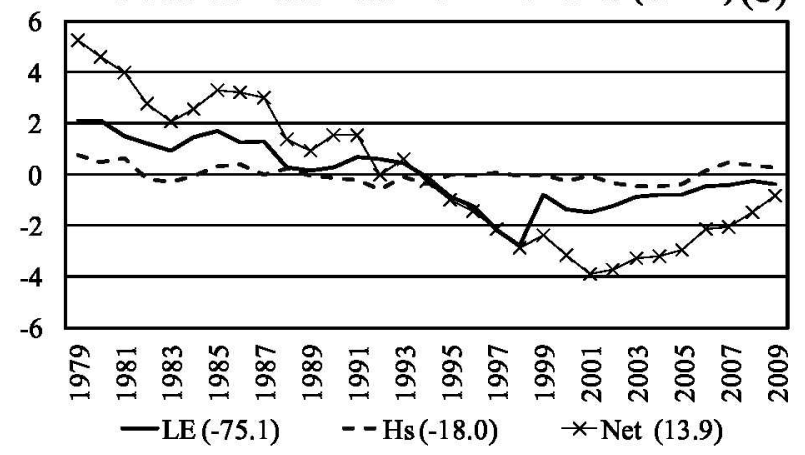

Global TOA Radiation Anomalies $\left(\mathbf{W ~ m}^{-2}\right) \quad$ (c)

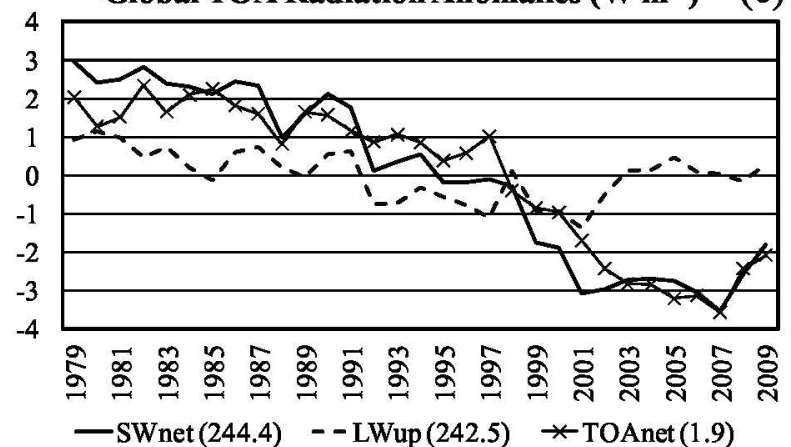

Figure 8 Global annual anomalies for (a) net radiation terms at the surface, shortwave (SWnet), longwave (LWnet) and the Net Radiation, (b) surface heat fluxes (positive down) including the Net heating and (c) radiation terms at the top of the atmosphere (TOA) net shortwave radiation (SWnet), upward longwave (LWup) and net top of atmosphere radiation (TOAnet). The means for each term are included in the legends. Units are in $\mathrm{W} \mathrm{m} \mathrm{m}^{-2}$. 
1

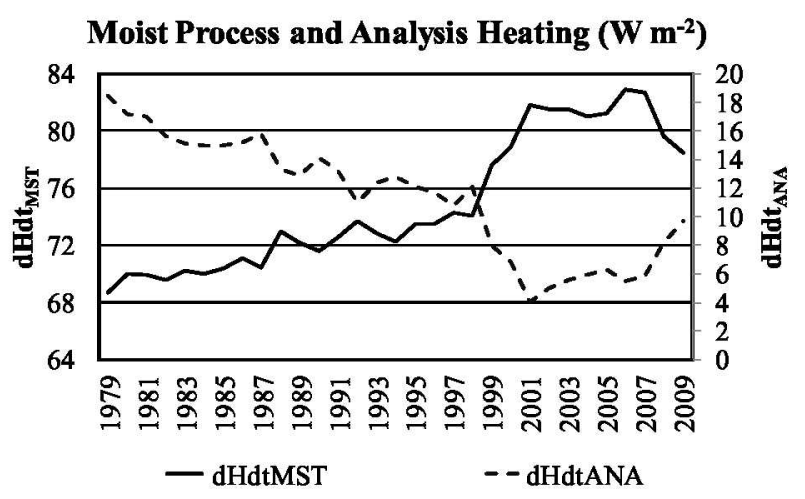

3

4 Figure 9 Energy terms for the moist processes (MST, essentially latent heating due to 5 precipitation) and the heating due to analysis increments. Units in $\mathrm{Wm}^{-2}$. 

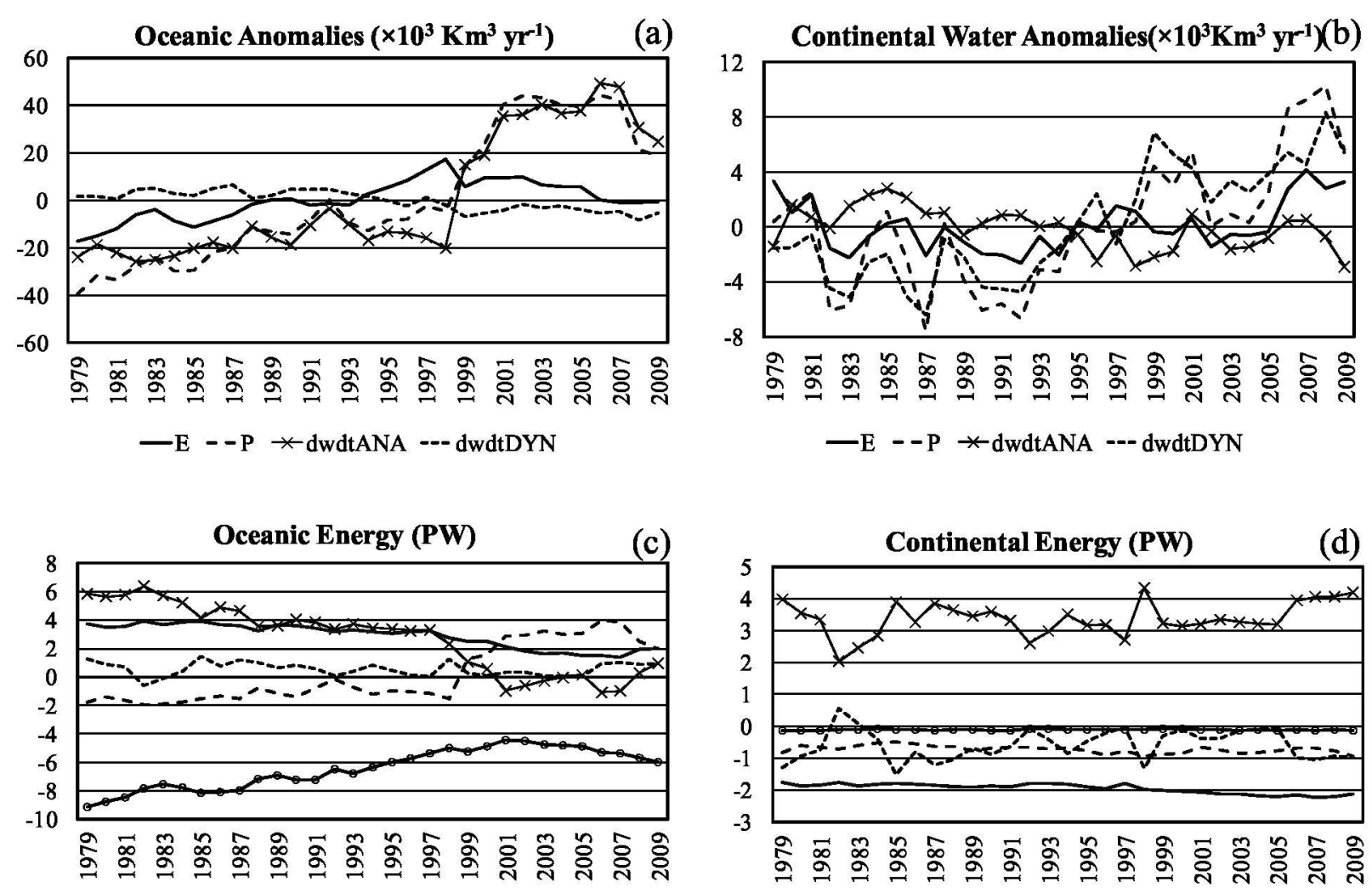

(c)

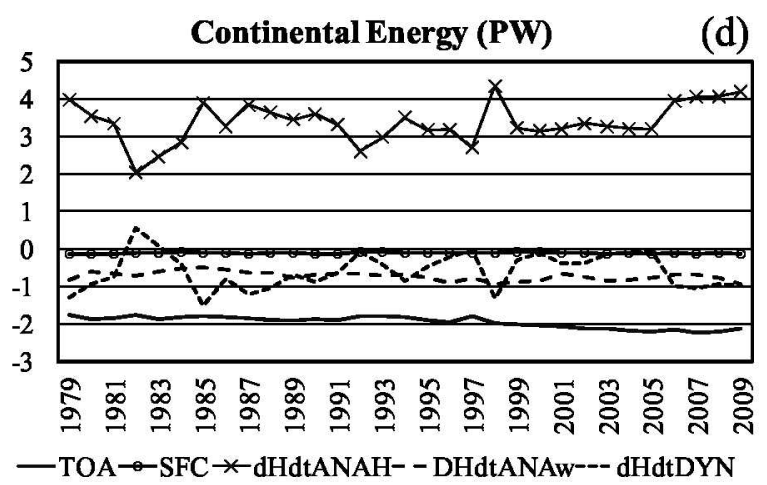

3 Figure 10 Separate terms for the integrated water mass and energy budgets over land and ocean

4 to compute land-ocean transport (a) ocean water budget anomalies, (b) continental budget (see

5 table 2 for the time means and variable definitions), (c) oceanic energy terms and (d) land energy 6 terms. 

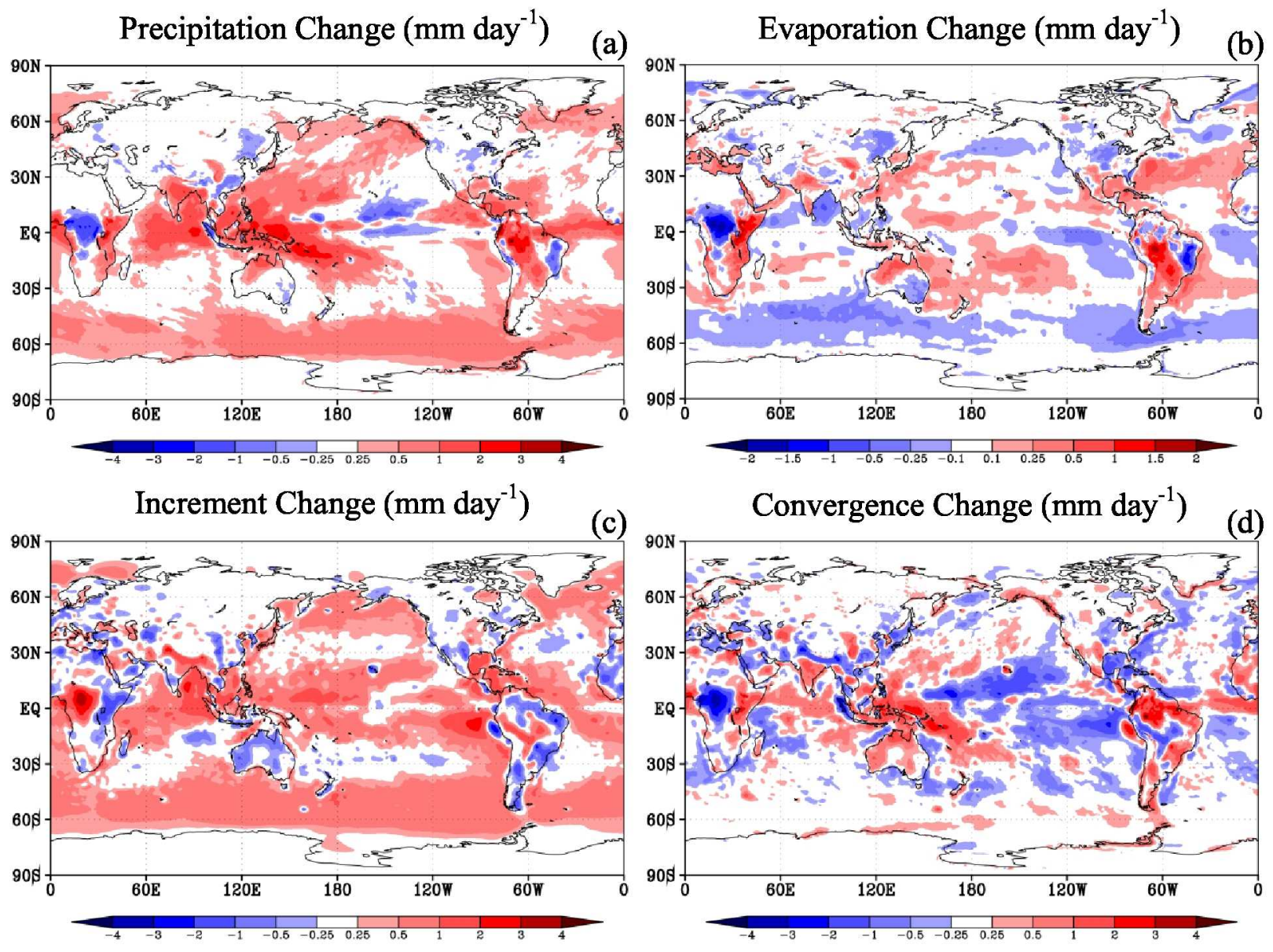

3 Figure 11 Change (2000-08 minus 1990-97, after AMSU minus before) of the atmospheric

4 hydrology budget terms Precipitation (a), Evaporation (b) Incremental Analysis Update for water

5 vapor (c) and moisture convergence (d). The change of evaporation is smaller than other terms

6 and is scaled different from other terms. 

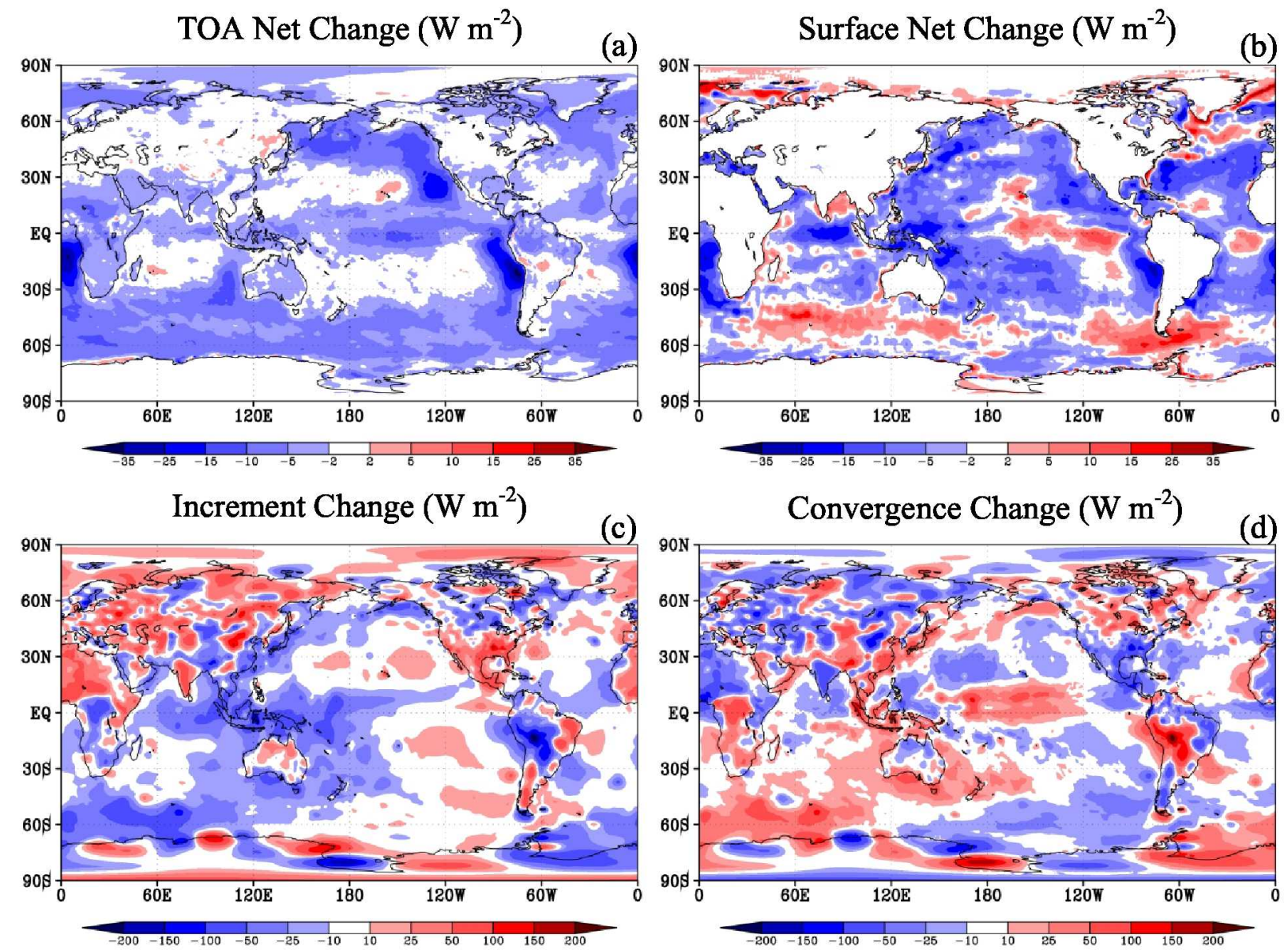

3 Figure 12 Change (2000-08 minus 1990-97, after AMSU minus before) of the atmospheric

4 energy budget terms Net TOA radiation (a) Net Surface Energy Flux (b), Incremental Analysis

$5 \quad$ Update for dry static heat (c) and heat convergence. 


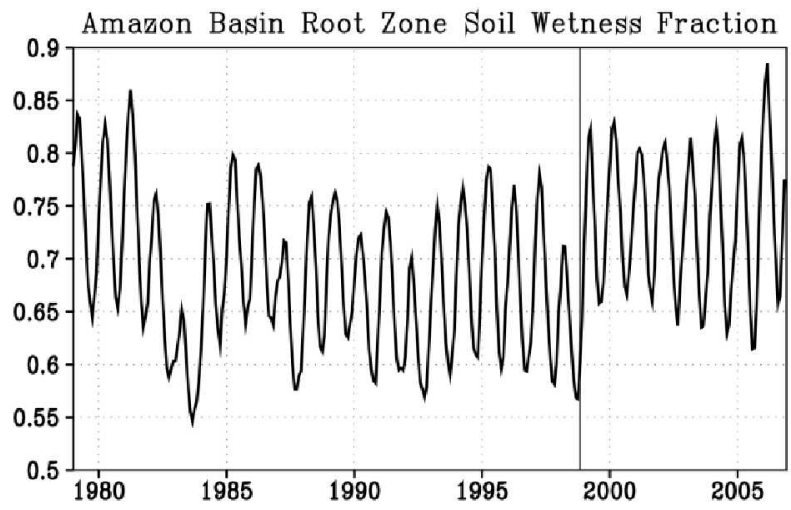

2 Figure 13 Time series of MERRA monthly mean root zone soil wetness fraction 3 (nondimensional), area averaged over the Amazon River basin.

4

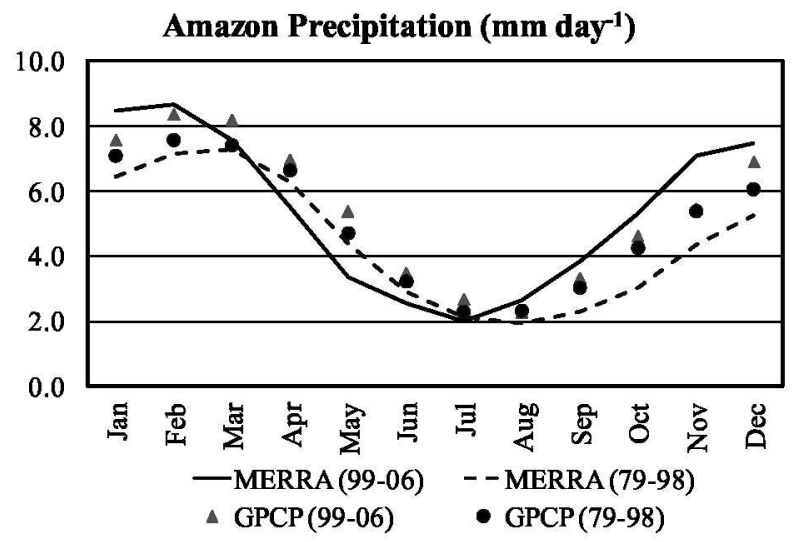

6 Figure 14 Mean annual cycle of monthly precipitation Area averaged over the Amazon River

7 basin from MERRA before AMSU data (1979-1998, dashed line) and MERAA when AMSU

8 data is assimilated (1999-2006), solid line, and also the corresponding GPCP (Adler et al. 2003)

9 basin averaged precipitation ( for 1979-1998, and $\boldsymbol{\Delta}$ for 1999-2006). Units are mm day ${ }^{-1}$. 


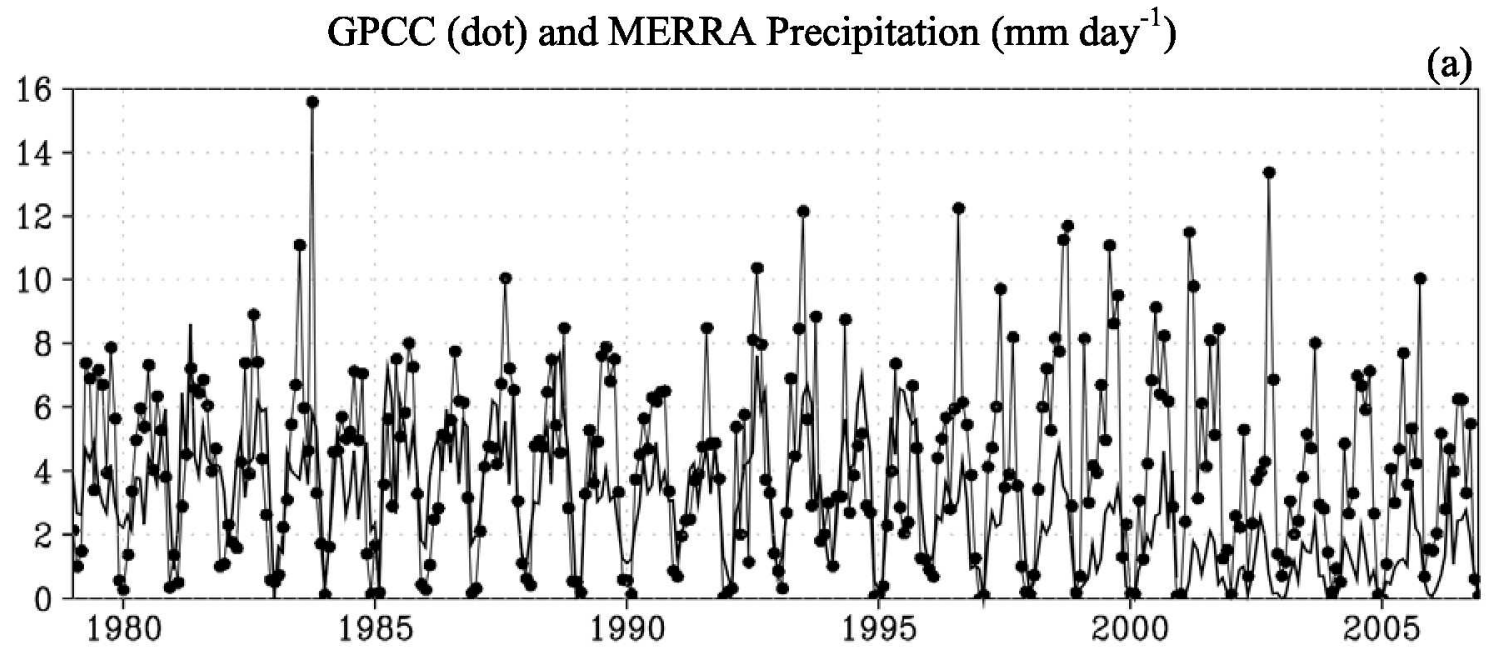

Radiosonde (dot) and MERRA Specific Humidity Anomaly (850 $\mathrm{mb} \mathrm{g} \mathrm{kg}^{-1}$ )

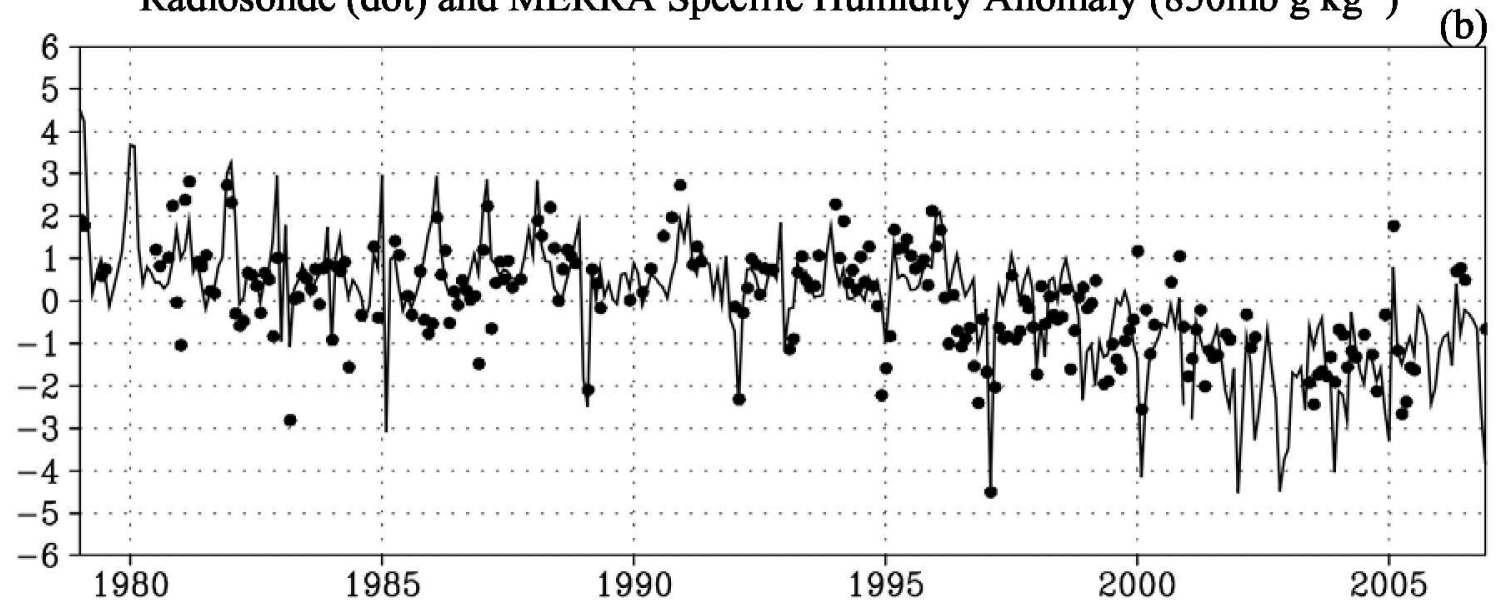

3 Figure 15 Time series of monthly MERRA data compared to observations at the MERRA point

$4 \quad\left(4.5^{\circ} \mathrm{N}, 18.67^{\circ} \mathrm{E}\right)$. (a) GPCC precipitation (dots with thin line; Schneider et al. 2008) and

5 MERRA precipitation (thick solid line) and (b) Bangui radiosonde observations (dots, station ID $64650,4.24^{\circ} \mathrm{N}, 18.31^{\circ} \mathrm{E}$ ) of $850 \mathrm{mb}$ specific humidity anomaly compared to MERRA. The 7 anomalies were calculated by removing the mean annual cycle. 